\title{
Fuzzy multi-objective optimization with $\alpha$-cut analysis for supply chain master planning problem
}

\author{
Noppasorn Sutthibutr ${ }^{\mathrm{a}}$ and Navee Chiadamrong ${ }^{\mathrm{a}^{*}}$
}

\begin{tabular}{|c|c|}
\hline CHRON I C LE & A B S T RAC T \\
\hline $\begin{array}{l}\text { Article history: } \\
\text { Received January 14, } 2019 \\
\text { Received in revised format April } \\
19,2019 \\
\text { Accepted April } 302019 \\
\text { Available online } \\
\text { April } 30 \text { 2019 } \\
\text { Keywords: } \\
\text { Supply Chain Master Planning } \\
\text { Possibilistic Linear Programming } \\
\text { Conflicting Objective } \\
\text { Fuzzy Goal Programming } \\
\alpha-C u t \text { Analysis }\end{array}$ & $\begin{array}{l}\text { This study considers a supply chain master planning problem in an uncertain environment } \\
\text { where operating costs, customer demand, production capacity, manufacturer's acceptable } \\
\text { defective rate, and manufacturer's acceptable service level are uncertain. Our supply chain } \\
\text { consists of one manufacturer, multiple suppliers, and multiple distribution centers. While one } \\
\text { objective is to minimize the total costs of logistics that consists of purchasing cost, production } \\
\text { cost, and distribution cost, the other objective is to maximize total value of purchasing. These } \\
\text { objectives are in conflict with each other. In this paper, the fuzzy multi-objective linear model } \\
\text { is applied with } \alpha \text {-Cut analysis to achieve the optimal supply chain master planning in an } \\
\text { uncertain environment by balancing these two conflicting objectives. The } \alpha \text {-Cut analysis is } \\
\text { introduced to ensure decision-makers that the outcome satisfies their preferences based on a } \\
\text { specified minimum allowed satisfaction value }(\alpha) \text {. }\end{array}$ \\
\hline
\end{tabular}

\section{Introduction}

A Supply Chain (SC) is a chain or network that coordinates the activities of five individual segments: supplier, manufacturer, distribution center, retailer, and customer, for serving products or services to satisfy customer requirements. To respond to customer demand, raw materials and resources are required to be manufactured, and then, delivered to distribution centers where the finished products are allocated to retailers and later sold to end customers. Without a supply chain's master plan, the procurement, production, and distribution plans are individually and independently executed in the supply chain, causing conflicting goals and operations. In the presence of increasingly competitive market pressure, supply chain master planning needs to assist firms in overcoming this issue. Supply chain master planning is mid-term decision planning (3-18 months) that integrates procurement, production, and distribution plans, to generate an efficient mutual supply chain master plan that meets the customer's needs and the organization's goal while achieving a competitive advantage.

\footnotetext{
* Corresponding author

E-mail address: navee@siit.tu.ac.th (N. Chiadamrong)

(C) 2019 by the authors; licensee Growing Science. doi: $10.5267 /$ j.uscm.2019.4.004
} 
Decision-makers have to face two major problems that may impact the overall performance of their supply chains. The first problem is from uncertainty. There is a lack of information or misleading information, which comes from two sources. First, environmental uncertainty is the uncertainty that is derived from the supplier's performance and the customer's behavior in terms of supply and demand. Variable supplier performance, late delivery, and defective raw materials can influence the supply. This can be referred to as supply uncertainty. Then, demand uncertainty such as imprecise judgment, inaccurate forecasts, and volatile consumer behavior is another type of uncertainty. Second, system uncertainty or process uncertainty includes the uncertainty in procurement, production, and distribution processes and unreliability of processes in a supply chain. Sometimes, fuzziness and uncertainty are subject to capacity. There is also the unreliability of processes that occur from machine breakdowns and variability in operating costs, times, and situations. The second problem is due to the conflicting objectives emerging from aligning goals from different supply chain echelons. Each echelon attempts to maximize or minimize its own inherent objective function or interest (e.g., minimize the total costs of logistics and maximize the customer service level or customer satisfaction).

Generally, a deterministic mathematical model cannot easily take the fuzziness into account. The theory of fuzzy sets is one of the best tools that can be used to handle uncertain information in supply chain master planning. A fuzzy programming model for decision-making in an uncertain environment was first proposed by Bellman and Zadeh (1970), and later it was applied to multi-objective linear programming problems by Zimmermann (1978). Zimmermann's model is a symmetric model because the fuzzy goals and fuzzy constraints are treated equivalently. However, a symmetric model may not be appropriate for multi-objective decision-making problems because the importance of the objectives is different for the decision-makers. In this study, the fuzzy multi-objective optimization for supply chain master planning is introduced to solve the conflicting objectives: (1) minimizing the total costs of logistics and (2)maximizing the total value of purchasing. Based on these conflicting objectives, our model can help decision-makers with optimal supply chain master planning that yields the lowest total costs while receiving good quality raw materials with on-time delivery.

In addition, the method of $\alpha$-Cut analysis is introduced into the fuzzy multi-objective linear programming model to define the minimum level of satisfaction. It attempts to increase the satisfaction of fuzzy objectives and constraints in the weightless method (Zimmermann's method). By balancing the conflicting objectives, our model yields an outcome for the obtained satisfaction of each fuzzy objective and constraint that can satisfy the decision-makers, based on their specified weight and minimum allowed satisfaction value $(\alpha)$.

The remaining paper is organized as follows. The related literature is reviewed in Section 2. The problem description, problem assumption, problem notation, and problem formation are described in Section 3. Section 4 proposes the methodology. A case study is demonstrated in Section 5, and the outcomes are presented in Section 6. Lastly, Section 7 is the conclusion of the study.

\section{Literature review}

Only relevant research that is related to supply chain master planning and related topics are reviewed here.

\subsection{Supply chain master planning}

There has been little research on the coordination of procurement, production, and distribution planning. Chan et al. (2005) considered a hybrid Genetic Algorithm (GA) for production and distribution planning by developing a model that hybridizes a Genetic Algorithm (GA) with an Analytic Hierarchy Process (AHP). Their proposed model provided reliable and robust results for production and distribution problems in multiple-factory cases. Pibernik and Sucky (2007) proposed an approach to inter-domain master planning in a supply chain by reviewing the problem that is related to centralized master planning and the deficiency of upstream planning mechanisms. Rudberg and Thulin (2008) studied a centralized supply chain master plan employing advanced planning systems as a decision 
support tool through Advanced Planning Systems (APS), which can rescue tactical supply chain master planning. Araini and Torabi (2018) studied integrated material-financial supply chain master planning under mixed uncertainty. They developed a bi-objective mixed possibilistic stochastic model that is superior to the original model for solving supply chain master planning. In addition, Vaziri et al. (2018) developed an integrated procurement and production design for a multiple-period and multiple-product manufacturing system with machine assignment and warehouse constraints. They proposed a procurement-production plan that combines Economic Order Quantity (EOQ) and Economic Production Quantity (EPQ) concepts for a multiple-period and multiple-product production-inventory system with limited warehouse capacity.

Supplier selection is one of the major topics in the supply chain management literature. To establish effective supply chain master planning, supplier selection is normally a multi-criteria decision-making problem (MCDM). For selecting the best supplier, potential suppliers are judged based on tangible and intangible criteria, in which some may interlace. However, it is rare that one supplier can outperform others in all criteria. For example, a supplier, who can supply good quality raw materials, may not sell the materials at the lowest price. To solve this supplier selection problem under uncertainty, several techniques have been developed, such as the Fuzzy Analytical Hierarchy Process (Fuzzy AHP), Fuzzy Technique for Order of Preference by Similarity to Ideal Solution (Fuzzy TOPSIS), and Analytical Hierarchy Process (AHP), etc. The Technique for Order of Preference by Similarity to Ideal Solution (TOPSIS) is one of several supplier selection techniques that were first developed by Hwang and Yoon in 1981. TOPSIS is used to evaluate the important weight of each supplier in this study. Chen et al. (2006) introduced Fuzzy TOPSIS to a supply chain, to select the qualified supplier by considering price, quality, and delivery performance. Azizi et al. (2015) proposed Fuzzy TOPSIS to determine an appropriate automotive supplier based on significant criteria and sub-criteria in industry. Kumar et al. (2018) used a Fuzzy TOPSIS model for selecting the suitable supplier for the small-scale manufacturing of steel in India based on the criteria of costs and benefits.

\subsection{Optimization in supply chain master planning}

Optimization methods are designed to encounter the 'best' values that lead to the highest system performance under the given constraints. To solve optimization problems, two kinds of algorithms can be used. First, the simplex algorithm or mathematical optimization is a popular algorithm for a linear programming model that is formulated to look for the optimal solution. This algorithm is usually used when the problem is simplex and small. Bittante et al. (2018) attempted to optimize a small-scale Liquefied Natural Gas (LNG) supply chain. They developed a mathematical model that considers the liquefied natural gas distribution to find the supply chain structure that minimizes the costs of fuel procurement. Kim et al. (2018) developed a robust optimization model for closed-loop supply chain planning under a reverse logistics flow and uncertain demand. They proposed a mathematical model and robust counterparts to deal with the uncertainty of recycled products and customer demand in the fashion industry. Koleva et al. (2018) studied an integration of the environmental aspects in modeling and optimization of water supply chains. They proposed a mathematical model for the design of water supply chains at regional and national scales by minimizing the total costs that are incurred from the capital and operating expenditures.

Second, simulation-based optimization with heuristic algorithms is designed for solving large optimization problems in a reasonable time. As an alternative to the mathematical models, it can be used to solve complex problems that take a long solving time or are beyond the ability of the mathematical models. Roy (2016) studied a simulation framework for the blocking effects in warehouse systems with autonomous vehicles. They developed a simulation model to address vehicle blocking. Their solutions suggest that blocking delays could account for $2 \%-20 \%$ of the transaction cycle times. Avci and Selim (2018) studied a multi-objective simulation-based optimization approach for inventory replenishment with premium freight in convergent supply chains. They developed a multi-objective simulation-based optimization model to solve the problem of inventory replenishment with premium 
freight in convergent supply chains by minimizing the total inventory cost, and setting the inbound and outbound premium freight ratios. Pires et al. (2018) studied a simulation-based optimization approach to integrate supply chain planning and control. They developed adaptive simulation-based optimization and Industry 4.0 technologies to integrate manufacturing supply chain planning tasks. Their model can deal with complex systems and can consider a dynamic environment with stochastic behavior.

In addition, a few research papers have tried to combine these two algorithms. While using mathematical model to find a global optimal result, the hybrid algorithm with the simulation model can recommend a result in an uncertain environment. For example, Nikolopoulou and Ierapetritou (2012) studied a hybrid simulation-based optimization approach for supply chain management. They proposed a hybrid simulation optimization approach. By combining the mathematical model with the simulation model, this hybrid approach can be used to address supply chain management problems.

In this study, supply chain master planning can be optimized based on the mathematical model. However, the model needs to be able to cope with aforementioned uncertainties and be able to solve conflicting objectives. We now review the related literature to classify the issues of interest.

\subsubsection{Number of objective functions}

Optimization in supply chain master planning can also be classified into two categories based on the number of objective functions. The first category is single-objective supply chain master planning where the model generates the optimal solution by setting control variables, corresponding to the minimum or maximum values of one objective function. The basic single-objective function in a supply chain minimizes the total costs or maximizes the total profit. Hajghasem (2016) studied the optimal routing in a supply chain, aiming to minimize the cost of vehicles. They proposed a model with a limited number of vehicles and different capacities. Their model performs network routing of transportation by minimizing the transportation costs. Batarfi et al. (2016) experimented with a dualchannel supply chain: a strategy to maximize profit. They investigated the effects of dual channels, traditional retail and online, on the performance of manufacturers and retailers based on maximizing the total profit.

Since it is difficult to consider only one objective along a supply chain, multi-objectives can be used to simultaneously interact among these different objectives. Multiple-objective supply chain master planning can be solved by creating a model that yields a set of compromised solutions with trade-offs among two or more conflicting objectives. Bilir et al. (2017) investigated an integrated multi-objective supply chain network and a competitive facility location model. They proposed a supply chain network and competitive facility models based on three utilized objective functions: maximizing profit, maximizing sales, and minimizing supply chain risk. García-Díaz et al. (2017) studied the bi-objective optimization of a multi-head weighing process. They proposed an algorithm to find the optimum operational conditions for their process. Mahmood and Mustafa (2018) studied a multi-objective approach for a supply chain design that considered disruptions of supply availability and poor product quality. They developed a multi-objective model with trade-offs among minimizing costs: operating cost, cost of unsatisfied demand, cost of shipping defective products, cost of inspecting quality, minimizing the risk that is incurred by the disruption.

Conflicting objectives can be caused when one objective contrasts another objective. This problem comes from trying to align the inherent goals of each echelon in a supply chain. Ghaithan et al. (2017) studied a multi-objective optimization model for a downstream oil and gas supply chain. They developed an integrated multi-objective oil-and-gas supply chain model with objective functions that: (1)minimize the total costs, (2)maximize the total revenue, and (3)maximize the service level for medium-term tactical decision making. Their model has trade-offs among several objectives. Decisionmakers can use their model for effective oil-and-gas supply chain management. Fathollahi-Fard and Hajiaghaei-Keshteli (2018) then explored a stochastic multi-objective model for a closed-loop supply chain by considering the environmental aspects. They developed a two-stage stochastic multi-objective 
model for a closed-loop supply chain with the environmental aspects and downside risk (at the same time). In our study, we have two conflicting objectives: (1)minimizing the total costs of logistics that yield the lowest possible total costs of purchasing, production, and distribution activities, and (2)maximizing the total value of purchasing, which is related to the price, quality, and service level of buying items from the supplier. A mathematical model is created to balance these two conflicting objectives by buying items from a reliable supplier with on-time delivery and good quality, considering the cheapest cost.

\subsubsection{Types of data}

In a supply chain, the recorded data can be deterministic and stochastic. The algorithms or approaches that help decision-makers to make a supply chain master plan can be sorted, based on different types of data. Linear Programming (LP) is generally formulated to solve the supply chain master planning problem with deterministic inputs or parameters. Spitter et al. (2005) studied linear programming models with planned lead times for supply chain operations planning. They proposed a linear programming model with a capacity constraint to solve a supply chain operation planning problem by minimizing the total costs: inventory and backordering costs. Matheus and Enzo (2016) employed linear programming methods for non-hierarchical spare parts supply chain planning. In their study, the linear programming model is evaluated by considering the capacity that is associated with spare parts in a supply chain.

In contrast, stochastic data can be described based on the theory of fuzzy sets. Fuzzy set theory is a theory of intuitive reasoning that relates to human subjective. The main concept is to arrest the abstruseness of human thinking and transform it into appropriate mathematical tools. Actually, human reasoning does not have only yes (true) or no (false) answers, but it also can have ambiguous answers that cannot be sharply defined. According to Werro (2015), ambiguity is a part of human thinking that is popular in natural languages. It can be divided into five different aspects: (1)incompleteness is the ambiguity from lacking information or knowledge, (2)homonymy is the ambiguity from incorrect interpretation due to a word, which has several possible meanings, (3)randomness is the ambiguity from unknown results that can happen in the future, (4)imprecision is the ambiguity from imprecise information, errors, or noise, and (5)fuzziness is the ambiguity with respect to words. In this study, our supply chain master planning problem relates to three aspects of fuzzy theory: incompleteness, randomness, and imprecision. Simic et al. (2017) explored 50 years of fuzzy set theory models for supplier evaluation and selection. Their paper shows how fuzzy set theory, fuzzy decision making, and hybrid solutions based on fuzzy set theory can solve the models of supplier assessment and selection.

\subsubsection{Mathematical approaches}

To cope with the stochastic inputs which are customer demand, operating costs, supplier and manufacturer production capacities, manufacturer's acceptable defective rate, and manufacturer's acceptable service level, Possibilistic Linear Programming (PLP) is used to depict imprecise data, based upon the trapezoidal or triangular distribution. Tuzkaya et al. (2008) proposed a two-phase possibilistic linear programming methodology for multi-objective supplier selection and order allocation problems. They applied the Analytic Hierarchy Process (AHP) to a multi-objective possibilistic linear programming model to evaluate and choose suppliers and to determine the optimum order quantities for each supplier. Kabak and Ulengin (2011) studied the possibilistic linear programming approach for supply chain networking decisions. To maximize the total profit of an organization, they proposed a possibilistic linear programming model with fuzzy demand, yield rate, costs, and capacities, to be used to make strategic resource-planning decisions.

To satisfy the multiple requirements of supply chains, Goal Programming (GP) is a traditional method that solves multiple objective supply chain master planning in a priority sequence where the secondpriority goal is run later, without decreasing the importance of the first-priority goal. Nixon et al. (2014) optimized the supply chain of pyrolysis plant deployment using GP. They developed a goal 
programming model to optimize the deployment of pyrolysis plants in Punjab. Hisjam et al. (2015) studied a sustainable partnership model among supply chain players in the wooden furniture industry using GP. They used GP to achieve 13 goals of a supply chain model for the wooden furniture industry in central Java and assigned different weights to different goals.

Fuzzy goal programming, sometimes called fuzzy mathematical programming with ambiguity, is an augmentation of traditional goal programming where the values of objective functions and constraints can be obscured. Kumar et al. (2004) introduced a fuzzy goal programming approach for a vendor selection problem in a supply chain. Fuzzy goal programming is applied for solving the problem of vendor selection and has three main objectives: (1)minimizing the net cost, (2)minimizing the net rejections, and (3)minimizing the net late deliveries. Nezhad et al. (2013) introduced a fuzzy goal programming approach to solve multi-objective supply chain network design problems. Fuzzy goal programming based on the fuzzy membership function can solve supply chain network design problems by minimizing the network costs and the amount of investment while maximizing the service level. Subulan et al. (2015) introduced a fuzzy goal programming model into a lead-acid battery closed-loop supply chain. A fuzzy-goal programming model with different priorities and importance is developed, based on the weighted geometric mean theory. Their model maximizes the collection of returned batteries, covered by the opened facilities. In this study, the Weighted Additive method (a fuzzy goal programming method) is introduced to optimize the supply chain master planning problem, in which different weights can be applied to various objectives based on decision-makers' preferences.

\subsection{4. $\alpha$-Cut analysis}

The $\alpha$-Cut is a constant set that belongs to the fuzzy set $\mathrm{B}$, in which the degree of its membership function exceeds the level of $\alpha: B_{\alpha}=\left[\mathrm{x} \in \mathrm{X} / \mu_{A}(\mathrm{x}) \geq \alpha\right]$. The $\alpha$-Cut analysis can be utilized to guarantee that the satisfaction of fuzzy goals and fuzzy constraints are higher than a minimum allowed value $(\alpha)$ that is derived from decision-makers. Bodjanova (2002) introduced the concept of $\alpha$-Cut analysis that is very important in the relationship between fuzzy sets and crisp sets. Naeni and Salehipour (2011) evaluated fuzzy earned value indices, which are estimated by applying $\alpha$-Cut. $\alpha$ Cut analysis was introduced into their model to improve the applicability of the earned value techniques under real-life and uncertain environments. Yang et al. (2016) proposed an improved $\alpha$ Cut analysis to transform the fuzzy membership function into basic belief assignment, which provides a bridge between the fuzzy set theory and the Dempster-Shafer Evidence Theory (DST). In this study, $\alpha$-Cut analysis is introduced into the fuzzy multi-objective linear programming model to assure that the degree of satisfaction for fuzzy goals and constraints is not less than a decision-maker's minimum allowed value $(\alpha)$

\section{Problem description}

A supply chain master planning problem can be described as three main sub-problems of planning: (1)procurement plan for identifying the quantity of items or raw materials that are procured from each supplier in each period, (2)production plan for defining the amount of each finished product that is manufactured in each period, and (3)distribution plan for determining the number of each final product that is distributed to each distribution center in each period. Our model obtains the optimal supply chain master planning decision by minimizing the total costs of logistics and maximizing the total value of purchasing over a mid-term horizon in an uncertain environment.

\subsection{Problem assumptions}

The assumptions used in formulating the supply chain master planning problem are elaborated as follows:

- Dynamic demand of each final product is assigned over the 12-month planning period.

- A set of qualified suppliers is given.

- Backorder and inventory's stockout are not allowed at each echelon in the supply chain. 
- Lead time is negligible by assuming that all parties in supply chain are close to each other.

- Supplier and manufacturer production capacities are varied because of various contingencies such as machine break downs, etc.

- Operating costs vary along the planning horizon.

- Manufacturer's acceptable defective rate and manufacturer's acceptable service level are imprecise, based on manufacturer's preferences.

\subsection{Problem notation}

To formulate the mathematical model, the symbol $\sim$ refers to ambiguous data that is used in this study. The notations of indexes, parameters, and decision variables are declared below:

\section{Indexes:}

\section{Parameters:}

$R W \quad$ inventory capacity of receiving warehouse at the manufacturer

$S W \quad$ inventory capacity of shipping warehouse at the manufacturer

TVP total value of purchasing

$\widetilde{M S L} \quad$ manufacturer's acceptable service level

$\widetilde{T C O} \quad$ cost of purchasing

$\widetilde{T C P} \quad$ production costs

$\widetilde{T C D} \quad$ distribution activity cost

$\widetilde{T C L} \quad$ total costs of logistics

$\widetilde{S C} \quad$ supplier cost

$\widetilde{O C} \quad$ ordering cost

$\widetilde{U C} \quad$ unit cost

Parameters that are related to weights:

$w_{h} \quad$ weights of fuzzy goals $(h=1, \ldots, 4)$

$\beta_{f} \quad$ weights of fuzzy constraints $(f=1)$

Parameters that have the index of items:

$\widetilde{M D R}_{l} \quad$ manufacturer's acceptable defective rate of the incoming item $i$

$I V R_{i} \quad$ unit storage volume required for item $i$

$I \widetilde{E I}_{0} \quad$ ending inventory of item $i$ at the manufacturer in period 0 
Parameters that have the index of suppliers:

$\widetilde{A S L}_{J} \quad$ average service level of supplier $j$

$\widetilde{T A C}_{J} \quad$ total associated cost of supplier $j$ over planning horizon

$W_{j} \quad$ weight of supplier $j$, considering performance

Parameters that have the index of finished products:

$F V R_{k} \quad$ unit storage volume required for finished product $k$

$\widetilde{F C R_{k}} \quad$ unit capacity requirement for finished product $k$ at the manufacturer

$s_{k} \quad$ safety factor of each finished product $k$

$F \widetilde{M E I}_{k o} \quad$ ending inventory of finished product $k$ at the manufacturer in period 0

Parameter that has the index of distribution centers:

$D W_{l} \quad$ inventory capacity at distribution center $l$

Parameter that has the index of periods:

$\widetilde{M C A P}_{t} \quad$ production capacity of the manufacturer in period $t$

Parameters that have two indexes of items and suppliers:

$\widetilde{I D R_{\iota \jmath}} \quad$ average defective rate of item $i$ supplied by supplier $j$

$\widetilde{I C R_{\iota j}} \quad$ unit capacity requirement of supplier $j$ for item $i$

Parameter that has two indexes of items and finished products:

$B_{i k} \quad$ amount of item $i$ required for producing one unit of finished product $k$

Parameter that has two indexes of items and periods:

$\widetilde{I H C_{l t}} \quad$ unit holding cost of item $i$ at period $t$

Parameters that have two indexes of suppliers and periods:

$\widetilde{U R_{J t}} \quad$ minimum acceptable utilization rate of capacity for supplier $j$ at period $t$

$\widetilde{S C A P}_{J t} \quad$ production capacity of supplier $j$ at period $t$

$\widetilde{T O C}_{J t} \quad$ total ordering cost of placing an order to supplier $j$ at period $t$

Parameter that has two indexes of finished products and distribution centers:

$F \widetilde{D E I}_{k l 0} \quad$ ending inventory of finished product $k$ at distribution center $l$ in period 0

Parameters that have two indexes of finished products and periods:

$\widetilde{F V C_{k t}} \quad$ unit variable production cost of finished product $k$ at period $t$

$F \widetilde{M H C}_{k t} \quad$ unit holding cost of finished product $k$ at the manufacturer in period $t$

Parameters that have three indexes of items, suppliers, and periods:

$\widetilde{I U P_{l j t}} \quad$ unit price of item $i$ charged by supplier $j$ at period $t$

$\widetilde{I A C_{l j t}} \quad$ additional unit cost of item $i$ purchased from supplier $j$ at period $t$ 
$\widetilde{I U C_{l j t}} \quad$ total unit level cost of item $i$ purchased from supplier $j$ at period $t$

$U B_{i j t} \quad$ upper bound of purchasing quantity of item $i$ from supplier $j$ in period $t$

Parameters that have three indexes of finished products, distribution centers, and periods:

$\widetilde{F S C_{k l t}} \quad$ shipping cost of finished product $k$ that is shipped to distribution center $l$ at period $t$

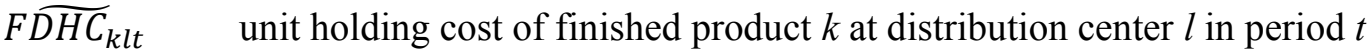

$\widetilde{d_{k l t}}$ customer demand of finished product $k$ at distribution center $l$ in period $t$

$\widetilde{S S_{k l t}}$ safety stock of finished product $k$ at distribution center $l$ in period $t$

Decision variables

$I E I_{i t} \quad$ ending inventory of item $i$ at the manufacturer in period $t$

$F P Q_{k t} \quad$ production quantity of finished product $k$ in period $t$

$F M E I_{k t} \quad$ ending inventory of finished product $k$ at the manufacturer in period $t$

$I P Q_{i j t} \quad$ purchasing quantity of item $i$ from supplier $j$ in period $t$

$S Q_{k l t} \quad$ shipping quantity of finished product $k$ to distribution center $l$ in period $t$

$F D E I_{k l t} \quad$ ending inventory of finished product $k$ at distribution center $l$ in period $t$

$\lambda_{0} \quad$ minimum satisfaction of objective functions

$\lambda_{h} \quad$ satisfaction of each objective function $h(h=1, \ldots, 4)$

$\gamma_{f} \quad$ satisfaction of each fuzzy constraint $f(f=1)$

Binary

$Z_{j} \quad 0$, otherwise 1 , if an order is placed with supplier $j$ over the decision horizon

$Y_{j t} \quad 0$, otherwise 1, if an order is placed with supplier $j$ in period $t$

\section{Problem formulation}

\subsection{Objective functions}

Minimization of the total costs of logistics and maximization of the total value of purchasing are the two main, but conflicting objectives in our supply chain master planning problem.

Minimizing the total costs of logistic. This objective is usually a concern of decision-makers when optimizing a supply chain. The total costs of logistics are a summation of the total costs of activities: purchasing, production, and distribution activities, in each echelon of a supply chain. It can be calculated as follows:

Minimize the total costs of logistics $=$ Costs of purchasing + Production costs + Distribution activity costs

$\min \widetilde{T C L}=\widetilde{T C O}+\widetilde{T C P}+\widetilde{T C D}$

Purchasing costs are incurred in all three levels of activities: supplier level activity, order level activity, and unit level activity. Costs of supplier activities are incurred from evaluating a supplier's performance and testing the quality of raw materials. Costs of ordering activities are derived from placing the orders 
to suppliers. Costs of unit level activities are related to procurement decisions such as unit price and inventory holding cost. The costs of purchasing are a summation of supplier level costs, ordering level costs, and unit level costs as shown below:

Costs of purchasing $=$ Supplier level costs + Ordering level costs + Unit level costs

$\widetilde{T C O}=\widetilde{S C}+\widetilde{O C}+\widetilde{U C}$

such that:

$$
\begin{aligned}
\widetilde{S C} & =\sum_{j=1}^{J} \widetilde{T A C_{J}} \times Z_{j} \\
\widetilde{O C} & =\sum_{t=1}^{T} \sum_{j=1}^{J} \widetilde{T O C_{j}} \times Y_{j t} \\
\widetilde{U C} & =\sum_{t=1}^{T} \sum_{j=1}^{J} \sum_{i \in P^{j}}\left(\widetilde{I U P_{l j t}}+\widetilde{I A C_{l \jmath t}}\right) \times I P Q_{i j t}+\sum_{t=1}^{T} \sum_{i=1}^{I} \widetilde{I H C_{l t}} \times I E I_{i t}
\end{aligned}
$$

Production costs are a summation of the variable production cost and inventory holding cost of the finished product $k$ at the manufacturer:

Production costs $=$ variable production costs + inventory holding cost of finished product $k$ at the manufacturer

$\widetilde{T C P}=\sum_{t=1}^{T} \sum_{k=1}^{K}\left({\widetilde{F V C_{k t}}}_{F P Q_{k t}}+F \widetilde{F H C}_{k t} \times F M E I_{k t}\right)$

Distribution activity costs are a summation of transportation cost and inventory holding cost of finished product $k$ at distribution center $l$.

Distribution activity costs $=$ transportation costs + inventory holding cost of finished product $k$ at distribution center $l$

$\widetilde{T C D}=\sum_{t=1}^{T} \sum_{l=1}^{L} \sum_{k=1}^{K}\left(\widetilde{F S C_{k l t}} \times S Q_{k l t}+F \widetilde{D H C}_{k l t} \times F D E I_{k l t}\right)$

Thus, the objective function of minimizing the total costs of logistics is as follows:

$$
\begin{aligned}
& \min \widetilde{T C L}=\sum_{j=1}^{J} \widetilde{T A C_{J}} \times Z_{j}+\sum_{t=1}^{T} \sum_{j=1}^{J} \widetilde{T O C_{j t}} \times Y_{j t}+\sum_{t=1}^{T} \sum_{j=1}^{J} \sum_{i \in P}\left(\widetilde{I U P_{l t t}}+\widetilde{I A C_{l j t}}\right) \times I P Q_{i j t} \\
& \quad+\sum_{t=1}^{T} \sum_{i=1}^{I} \widetilde{I H C_{l t}} \times I E I_{i t}+\sum_{t=1}^{T} \sum_{k=1}^{K}\left(\widetilde{F V C_{k t}} \times F P Q_{k t}+F \widetilde{M H C}_{k t} \times F M E I_{k t}\right) \\
& \quad+\sum_{t=1}^{T} \sum_{l=1}^{L} \sum_{k=1}^{K}\left(\widetilde{F C_{k l t}} \times S Q_{k l t}+F D H C_{k l t} \times F D E I_{k l t}\right)
\end{aligned}
$$

Maximizing the total value of purchasing. This objective can be used as purchasing criteria for price, quality of provided items, and service level, that are considered in the procurement planning. It is computed as follows:

Maximize the total value of purchasing $=$ weight of supplier $j \times$ purchasing quantity of item $i$ from supplier $j$ in period $t$

$$
\max \mathrm{TVP}=\sum_{j=1}^{J} W_{j} \times \sum_{t=1}^{T} \sum_{i=1}^{I} I P Q_{i j t}
$$

Note: different weights of supplier $\left(W_{j}\right)$ can be estimated from decision-makers' experience. For instance, ranking and scoring models such as the Technique for Order of Preference by Similarity to Ideal Solution (TOPSIS) can help to find the suitable weight of each supplier.

\subsection{Constraints}

There are four major constraints: inventory level, capacity, quality, and service level constraints, that are used for supply chain master planning.

\subsubsection{Inventory level constraints}

Demand of item at manufacturer $=$ Ending inventory of item $i$ at the manufacturer in period 0 
+ Purchasing quantity of item $i$ from supplier $j$ in period $t$

- Ending inventory of item $i$ at the manufacturer in period $t$

$$
\sum_{k} B_{i k} \times F P Q_{k t}=I E I_{i, t-1}+\sum_{j} I P Q_{i j t}-I E I_{i t} \quad \forall i, t
$$

Note: The demand of an item at the manufacturer equals the amount of an item required for producing one unit of finished product, multiplied by the production quantity of finished product $k$ in period $t$.

Quantity of shipped finished product $=$ Ending inventory of finished product $k$ at the manufacturer

in period $0+$ Production quantity of finished product $k$ in period $t$

+ Ending inventory of finished product $k$ at the manufacture in period $t$

$\sum_{l} S Q_{k l t}=F M E I_{k, t-1}+F P Q_{k t}-F M E I_{k t} \quad \forall k, t$

Demand of finished product $=$ Ending inventory of finished product $k$ at distribution center $l$

in period $0+$ Shipping quantity of finished product $k$ to distribution center $l$ in period $t$

- Ending inventory of finished product $k$ at distribution center $l$ in period $t$

$$
\widetilde{d_{k l t}}=F D E I_{k l, t-1}+S Q_{k l t}-F D E I_{k l t} \quad \forall k, l, t
$$

Ending inventory of finished product $k$ at distribution center $l$ in period $t \geq$ Safety stock of finished product $k$ at distribution center $l$ in period $t$

$$
F D E I_{k l t} \geq \widetilde{S S_{k l t}} \quad \forall k, l, t
$$

Note: $\widetilde{S S_{k l t}}=\alpha_{k} \times \widetilde{d_{k l, t+1}}$ where $\alpha_{k}$ denotes a safety factor of finished product $k$.

Constraints (3) and (4) are inventory balancing constraints for items and finished products that involve the manufacturer. Constraints (5) and (6) indicate the finished product inventory balancing and the level of safety stock at the distribution center, respectively.

\subsubsection{Capacity constraints}

Unit capacity requirement of supplier $j$ for item $i \times$ Purchasing quantity of item $i$ from supplier $j$ in period $t \leq$ Production capacity of supplier $j$ at period $t$

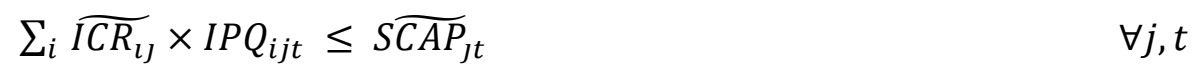

Unit capacity requirement of supplier $j$ for item $i \times$ Purchasing quantity of item $i$ from supplier $j$ in period $t \geq$ Minimum acceptable utilization rate of capacity for supplier $j$ at period $t \times$ Production capacity of supplier $j$ at period $t \times$ An order is placed or not with supplier $j$ in period $t$

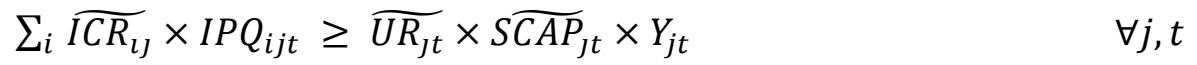

Unit capacity requirement for finished product $k$ at the manufacturer $\times$ Production quantity of finished product $k$ in period $t \leq$ Production capacity of the manufacturer in period $t$

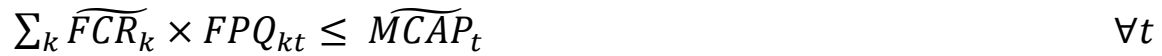

The above constraints are associated with the level of production capacity at the suppliers and the manufacturer. Maximum and minimum production capacities utilized by the supplier are Constraints (7) and (8), respectively. The limitation of manufacturer's production capacity is shown in Constraint (9).

Unit storage volume required for item $i \times$ Ending inventory of item $i$ at the manufacturer in period $t \leq$ Inventory capacity of the receiving warehouse at the manufacturer 


$$
\sum_{i} I V R_{i} \times I E I_{i t} \leq R W \quad \forall t
$$

Unit storage volume required for finished product $k \times$ Ending inventory of finished product $k$ at the manufacturer in period $t \leq$ Inventory capacity of the shipping warehouse at the manufacturer

$$
\sum_{k} F V R_{k} \times F M E I_{k t} \leq S W \quad \forall t
$$

Unit storage volume required for finished product $k \times$ Ending inventory of finished product $k$ at distribution center $l$ in period $t \leq$ Inventory capacity at distribution center $l$

$$
\sum_{k} F V R_{k} \times F D E I_{k l t} \leq D W_{l} \quad \forall t
$$

Constraints (10) and (11) impose a storage space for the receiving and shipping warehouses at the manufacturer. Constraint (12) presents the limited space for storage at the distribution center.

\subsubsection{Quality constraint}

Average defective rate of item $i$ supplied by supplier $j \times$ Purchasing quantity of item $i$ from supplier $j$ in period $t \leq$ Manufacturer's acceptable defective rate of an incoming item $i \times$ Purchasing quantity of item $i$ from supplier $j$ in period $t$

$$
\sum_{j \in S^{i}} \widetilde{I D R_{\imath \jmath}} \times I P Q_{i j t} \leq \widetilde{M D R}_{\iota} \times \sum_{j \in S^{i}} I P Q_{i j t} \quad \forall i, t
$$

\subsubsection{Service level constraint}

Average service level of supplier $j \times$ Purchasing quantity of item $i$ from supplier $j$ in period $t \geq$ Manufacturer's acceptable service level $\times$ Purchasing quantity of item $i$ from supplier $j$ in period $t$

$$
\sum_{i} \sum_{j} \overline{A S L_{J}} \times I P Q_{i j t} \geq \widehat{M S L} \times \sum_{i} \sum_{j} I P Q_{i j t} \quad \forall t
$$

Quality and service level constraints are restrictions that can be used to evaluate the performance of a supplier, as shown in Constraints (13) and (14).

\subsubsection{Constraints on variables}

Purchasing quantity of item $i$ from supplier $j$ in period $t \leq$ Upper bound of purchasing quantity of item $i$ from supplier $j$ in period $t \times$ An order is placed or not with supplier $j$ in period $t$

$$
I P Q_{i j t} \leq U B_{i j t} \times Y_{j t} \quad \forall i, j, t
$$

Note: $U B_{i j t}=\min \left(\frac{s C A P_{j t}^{o}}{I C R_{i j}^{p}}, \sum_{t=1}^{T} \sum_{k=1}^{K} \sum_{l=1}^{L} B_{i k} d_{k l t}^{o}\right)$, which is used to limit the amount of item $i$, placed at each supplier.

$$
\begin{array}{lc}
Z_{j} \leq \sum_{t} Y_{j t} & \forall j \\
Y_{j t} \leq Z_{j} & \forall j, t \\
Y_{j t}, Z_{j} \in\{0,1\} & \forall j, t
\end{array}
$$

\subsubsection{Non-negativity constraint}

$$
I E I_{i t}, F P Q_{k t}, F M E I_{k t}, I P Q_{i j t}, S Q_{k l t}, F D E I_{k l t} \geq 0 \quad \forall i, j, k, l, t
$$

Constraints (16) and (17) are integrality constraints for when the model does not recommend to buy item $i$ from supplier $j$ over the planning horizon. Constraint (16) forces $Z_{j}$ to be equal to zero, while Constraint (17) forces $Z_{j}$ to be equal to one if an order is placed with supplier $j$ in some periods. Constraints (18) and (19) indicate that all decision variables are non-negative. 


\section{Solution methodology}

\subsection{Possibilistic Linear Programming}

Possibilistic Linear Programming (PLP) is introduced into the supply chain master planning model. PLP is subject to imprecise parameters: operating costs, customer demand, supplier and manufacturer production capacities, manufacturer's acceptable defective rate, and manufacturer's acceptable service level. These parameters are random, based on the triangular (possibility) distribution.

\subsubsection{Triangular (possibility) distribution}

The usual possibility distribution (found in applications of fuzzy sets) is the triangular fuzzy number, completely defined by its support. Triangular fuzzy numbers can be used for representing uncertainty within an interval. Indeed, the triangular distribution is an optimal transform of the uniform probability distribution. It is the upper envelope of all the possibility distributions, transformation from symmetric probability densities with the same support (Dubois et al. 2004).

A triangular fuzzy number can be used to express the vagueness and uncertainty of information and to represent fuzzy terms in information processing. Triangular fuzzy numbers have been applied in many fields such as risk evaluation, performance evaluation, forecast, matrix games, decision-making, and spatial representation. In principle, membership functions can be different shapes, but in practice, trapezoidal and triangular membership functions are the most frequently used (Zhang et al. 2014). The triangular distribution is a continuous distribution that defines the range $\mathrm{x} \in[\mathrm{a}, \mathrm{b}]$ with the probability density function, as expressed in Eq. (20) below. The triangular (possibility) distribution is based on three prominent data points, as shown in Fig. 1.

$\mathrm{P}(\mathrm{x})=\left\{\begin{array}{l}\frac{2\left(x-a_{n t}^{o}\right)}{\left(a_{n t}^{m}-a_{n t}^{o}\right)\left(a_{n t}^{p}-a_{n t}^{o}\right)}, a_{n t}^{o}<x<a_{n t}^{p} \\ \frac{2\left(a_{n t}^{m}-x\right)}{\left(a_{n t}^{m}-a_{n t}^{o}\right)\left(a_{n t}^{m}-a_{n t}^{p}\right)}, a_{n t}^{p}<x<a_{n t}^{m}\end{array}\right\}$

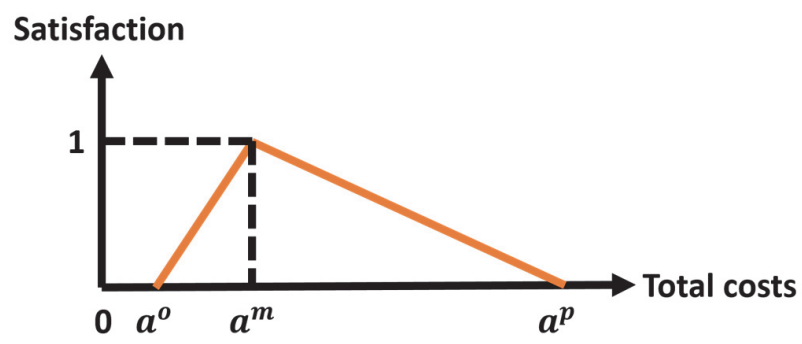

Fig. 1. Triangular distribution

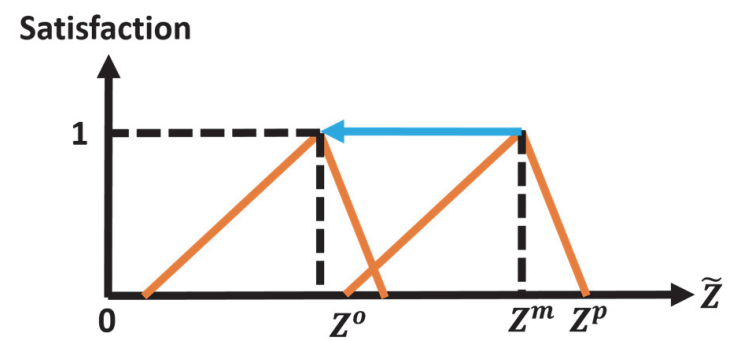

Fig. 2. Minimizing the total costs of logistics

Fig. 1 shows three prominent points: the most likely value point, the optimistic value point, and the pessimistic value point. These points can be used to describe the triangular distribution as below:

- The optimistic value $\left(a^{o}\right)$ is the value that yields the best case. There is a very low likelihood that possibility degree $=0$ if normalized.

- The most likely value $\left(a^{m}\right)$ is the value that yields the normal or general case. There is a very low likelihood that possibility degree $=1$ if normalized.

- The pessimistic value $\left(a^{p}\right)$ is the value that yields the worst case. There is a very low likelihood that possibility degree $=0$ if normalized.

Fig. 2 shows three prominent point: optimistic cost $\left(z^{o}\right)$, most likely cost $\left(z^{m}\right)$, pessimistic $\operatorname{cost}\left(z^{p}\right)$. These points are used for minimizing the total costs of logistics. Because of uncertain costs, the objective function for minimizing the total costs of logistics can be divided into 3 objective functions: (1) minimizing the most likely total costs of logistics (minimizing $z^{m}$ ), (2) maximizing the lower total 
costs of logistics (maximizing $z^{m}-z^{o}$ ), and (3) minimizing the higher total costs of logistics (minimizing $z^{p}-z^{m}$ ) by pushing these three values toward the left.

\section{Objective functions}

After applying possibilistic linear programming to the Linear Programming (LP) model, the crisps of objective functions of the total costs of logistics are shown below.

Minimizing the most likely total costs of logistics

$$
\begin{aligned}
& \min T C L_{1}=z^{m}=\sum_{j=1}^{J} T A C_{j}^{m} \times Z_{j}+\sum_{t=1}^{T} \sum_{j=1}^{J} T O C_{j t}^{m} \times Y_{j t} \\
& \quad+\sum_{t=1}^{T} \sum_{j=1}^{J} \sum_{i \in P^{j}}\left(I U P_{i j t}^{m}+I A C_{i j t}^{m}\right) \times I P Q_{i j t} \\
& \quad+\sum_{t=1}^{T} \sum_{i=1}^{I} I H C_{i t}^{m} \times I E I_{i t}+\sum_{t=1}^{T} \sum_{k=1}^{K}\left(F V C_{k t}^{m} \times F P Q_{k t}+F M H C_{k t}^{m} \times F M E I_{k t}\right) \\
& \quad+\sum_{t=1}^{T} \sum_{l=1}^{L} \sum_{k=1}^{K}\left(F S C_{k l t}^{m} \times S Q_{k l t}+F D H C_{k l t}^{m} \times F D E I_{k l t}\right)
\end{aligned}
$$

Maximize the lower total costs of logistics

$$
\begin{aligned}
\max & T C L_{2}=\left(z^{m}-z^{o}\right)=\sum_{j=1}^{J}\left(T A C_{j}^{m}-T A C_{j}^{o}\right) \times Z_{j}+\sum_{t=1}^{T} \sum_{j=1}^{J}\left(T O C_{j t}^{m}-T O C_{j t}^{o}\right) \times Y_{j t} \\
& +\sum_{t=1}^{T} \sum_{j=1}^{J} \sum_{i \in P^{j}}\left(\left(I U P_{i j t}^{m}-I U P_{i j t}^{o}\right)+\left(I A C_{i j t}^{m}-I A C_{i j t}^{o}\right)\right) \times I P Q_{i j t} \\
& +\sum_{t=1}^{T} \sum_{i=1}^{I}\left(I H C_{i t}^{m}-I H C_{i t}^{o}\right) \times I E I_{i t} \\
& +\sum_{t=1}^{T} \sum_{k=1}^{K}\left(\left(F V C_{k t}^{m}-F V C_{k t}^{o}\right) \times F P Q_{k t}+\left(F M H C_{k t}^{m}-F M H C_{k t}^{o}\right) \times F M E I_{k t}\right) \\
& +\sum_{t=1}^{T} \sum_{l=1}^{L} \sum_{k=1}^{K}\left(\left(F S C_{k l t}^{m}-F S C_{k l t}^{o}\right) \times S Q_{k l t}+\left(F D H C_{k l t}^{m}-F D H C_{k l t}^{o}\right) \times F D E I_{k l t}\right)
\end{aligned}
$$

Minimize the higher total costs of logistics

$$
\begin{aligned}
\min & T C L_{2}=\left(z^{p}-z^{m}\right) \\
& =\sum_{j=1}^{J}\left(T A C_{j}^{p}-T A C_{j}^{m}\right) \times Z_{j}+\sum_{t=1}^{T} \sum_{j=1}^{J}\left(T O C_{j t}^{p}-T O C_{j t}^{m}\right) \times Y_{j t} \\
& +\sum_{t=1}^{T} \sum_{j=1}^{J} \sum_{i \in P^{j}}\left(\left(I U P_{i j t}^{p}-I U P_{i j t}^{m}\right)+\left(I A C_{i j t}^{p}-I A C_{i j t}^{m}\right)\right) \times I P Q_{i j t} \\
& +\sum_{t=1}^{T} \sum_{i=1}^{I}\left(I H C_{i t}^{p}-I H C_{i t}^{m}\right) \times I E I_{i t} \\
& +\sum_{t=1}^{T} \sum_{k=1}^{K}\left(\left(F V C_{k t}^{p}-F V C_{k t}^{m}\right) \times F P Q_{k t}+\left(F M H C_{k t}^{p}-F M H C_{k t}^{m}\right) \times F M E I_{k t}\right) \\
& +\sum_{t=1}^{T} \sum_{l=1}^{L} \sum_{k=1}^{K}\left(\left(F S C_{k l t}^{p}-F S C_{k l t}^{m}\right) \times S Q_{k l t}\right. \\
& \left.+\left(F D H C_{k l t}^{p}-F D H C_{k l t}^{m}\right) \times F D E I_{k l t}\right)
\end{aligned}
$$

In addition, the other objective function maximizes the total value of purchasing. This is a crisp objective function, as there is no uncertainty related to the purchasing criteria. Its objective function can be presented as follow:

Maximize the total value of purchasing

$$
\max \mathrm{TVP}=\sum_{j=1}^{J} W_{j} \times \sum_{t=1}^{T} \sum_{i=1}^{I} I P Q_{i j t}
$$

\section{Constraints}

Constraints can be classified into two types: crisp and fuzzy (or soft constraints). Crisp constrains refer to constraints where there is no uncertainty (i.e., Eqs. (3-4), Eqs. (10-12), and Eqs. (15-19)). The remaining equations are fuzzy constraints involving imprecise values that must be transformed to crisp constraints by using the defuzzification method. 
Crisp constraints

$$
\begin{array}{ll}
\sum_{k} B_{i k} \times F P Q_{k t}=I E I_{i, t-1}+\sum_{j \in S^{i}} I P Q_{i j t}-I E I_{i t} & \forall i, t \\
\sum_{l} S Q_{k l t}=F M E I_{k, t-1}+F P Q_{k t}-F M E I_{k t} & \forall k, t \\
\sum_{i} I V R_{i} \times I E I_{i t} \leq R W & \forall t \\
\sum_{k} F V R_{k} \times F M E I_{k t} \leq S W & \forall t \\
\sum_{k} F V R_{k} \times F D E I_{k l t} \leq D W_{l} & \forall t \\
I P Q_{i j t} \leq U B_{i j t} \times Y_{j t} & \forall i, j, t \\
Z_{j} \leq \sum_{t} Y_{j t} & \forall t \\
Y_{j t} \leq Z_{j} & \forall j, t \\
Y_{j t}, Z_{j} \in\{0,1\} & \forall j, t \\
I E I_{i t}, F P Q_{k t}, F M E I_{k t}, I P Q_{i j t}, S Q_{k l t}, F D E I_{k l t} \geq 0 & \forall i, j, k, l, t
\end{array}
$$

\subsection{Defuzzification method}

The defuzzification method converts imprecise data into crisp data. Here, we use two kinds of defuzzification methods: weighted average and fuzzy ranking. The weighted average method can be used to defuzzify fuzzy constraints that have fuzzy values on one side of an equation. In contrast with the fuzzy ranking method, it can also be used to defuzzify fuzzy constraints where both sides of an equation contain fuzzy data.

\subsubsection{Weighted average method}

Referring to Eq. (5), the demand for finished products $\left(\widetilde{d_{k l t}}\right)$ has imprecise value under the triangular distribution. Converting the demand value by applying the weighted average method is presented below.

$$
w_{1}^{o} d_{k l t}^{o}+w_{2}^{m} d_{k l t}^{m}+w_{3}^{p} d_{k l t}^{p}=F D E I_{k l, t-1}+S Q_{k l t}-F D E I_{k l t} \quad \forall k, l, t
$$

The weights are assigned to the imprecise demand for finished products by decision-makers, based on their experience. The weights of the most pessimistic, the most likely, and the most optimistic are denoted as $w_{1}^{o}, w_{2}^{m}$, and $w_{3}^{p}$. The summation of weights must be equal to $1\left(w_{1}^{o}+w_{2}^{m}+w_{3}^{p}=1\right)$.

For example, assuming 1,500, 1,200, and 1,000 units are the optimistic value of demand for finished products $\left(d_{k l t}^{o}\right)$, the most likely value of demand for finished products $\left(d_{k l t}^{m}\right)$, and the pessimistic value of demand for finished products $\left(d_{k l t}^{p}\right)$ in the first month, respectively, and $33 \%$ are equally distributed to $w_{1}^{o}, w_{2}^{m}$, and $w_{3}^{p}$. Eq. (35) is calculated as follows:

$$
\begin{array}{cc}
(0.33 \times 1,000)+(0.33 \times 1,200)+(0.33 \times 1,500)=F D E I_{k l, t-1}+S Q_{k l t}-F D E I_{k l t} & \forall k, l, t \\
1,221 \text { units }=F D E I_{k l, t-1}+S Q_{k l t}-F D E I_{k l t} & \forall k, l, t
\end{array}
$$

Similarly, Eq. (6) where the safety stock of finished products has an imprecise value can be converted to the crisp value as follows:

$$
F D E I_{k l t} \geq w_{1}^{o} S S_{k l t}^{o}+w_{2}^{m} S S_{k l t}^{m}+w_{3}^{p} S S_{k l t}^{p} \quad \forall k, l, t
$$

For example, assume that 75, 60, and 50 units are the optimistic values of safety stock for finished products $\left(d_{k l t}^{o}\right)$, the most possible value of safety stock for finished products $\left(d_{k l t}^{m}\right)$, and the pessimistic 
value of safety stock for finished products $\left(d_{k l t}^{p}\right)$, respectively, in the first month, and $33 \%$ is equally distributed to $w_{1}^{o}, w_{2}^{m}$, and $w_{3}^{p}$. Eq. (36) is calculated as follows:

$F D E I_{k l t} \geq(0.33 \times 50)+(0.33 \times 60)+(0.33 \times 75) \quad \forall k, l, t$

$F D E I_{k l t} \geq 61$ units

\subsubsection{Fuzzy ranking method}

In addition, the fuzzy ranking method can be used to defuzzify imprecise data. It does not require weight allocation to prioritize the importance of data. Fuzzy ranking is applied to Eqs. (7)-(9) and Eqs. (13)-(14) as follows:

From Eq. (7), the unit capacity requirement of item $\left(\widetilde{I C R_{l J}}\right)$ and the production capacity of a supplier $\left(S \widetilde{C A P}_{J t}\right)$ are uncertain. Converting these two values to crisp values through the fuzzy ranking method is presented below:

$$
\begin{array}{lr}
\sum_{i} I C R_{i j}^{o} \times I P Q_{i j t} \leq S C A P_{j t}^{o} & \forall j, t \\
\sum_{i} I C R_{i j}^{m} \times I P Q_{i j t} \leq S C A P_{j t}^{m} & \forall j, t \\
\sum_{i} I C R_{i j}^{p} \times I P Q_{i j t} \leq S C A P_{j t}^{p} & \forall j, t
\end{array}
$$

For example, assume that the pessimistic value of the production capacity of a supplier $\left(S C A P_{j t}^{o}\right)$, the most likely value of production capacity of a supplier $\left(S C A P_{j t}^{m}\right)$, and the optimistic value of production capacity of a supplier $\left(S C A P_{j t}^{p}\right)$ in the first month are equal to 2,000, 2,600, and 3,100 units, respectively, Eqs. (37) - (39) are formulated as follows.

$$
\begin{array}{lr}
\sum_{i} I C R_{i j}^{o} \times I P Q_{i j t} \leq 2,000 & \forall j, t \\
\sum_{i} I C R_{i j}^{m} \times I P Q_{i j t} \leq 2,600 & \forall j, t \\
\sum_{i} I C R_{i j}^{p} \times I P Q_{i j t} \leq 3,100 & \forall j, t
\end{array}
$$

For Equation (8), the unit capacity requirement of an item $\left(\widetilde{I C R_{l J}}\right)$, the minimum acceptable utilization rate of capacity $\left(\widetilde{U R_{J t}}\right)$, and the production capacity of a supplier $(\widetilde{S C A P}$,$) are uncertain. They can be$ converted to crisp values as follows:

$$
\begin{array}{lr}
\sum_{i} I C R_{i j}^{o} \times I P Q_{i j t} \geq U R_{j t}^{o} \times S C A P_{j t}^{o} \times Y_{j t} & \forall j, t \\
\sum_{i} I C R_{i j}^{m} \times I P Q_{i j t} \geq U R_{j t}^{m} \times S C A P_{j t}^{m} \times Y_{j t} & \forall j, t \\
\sum_{i} I C R_{i j}^{p} \times I P Q_{i j t} \geq U R_{j t}^{p} \times S C A P_{j t}^{p} \times Y_{j t} & \forall j, t
\end{array}
$$

For Eq. (9), the unit capacity requirement of finished products $\left(\widetilde{F C R_{k}}\right)$ and the production capacity of the manufacturer $\left(\widetilde{M C A P}_{t}\right)$ are uncertain and are converted to crisp values as follows:

$$
\begin{array}{lc}
\sum_{k} F C R_{k}^{o} \times F P Q_{k t} \leq M C A P_{t}^{o} & \forall t \\
\sum_{k} F C R_{k}^{m} \times F P Q_{k t} \leq M C A P_{t}^{m} & \forall t \\
\sum_{k} F C R_{k}^{p} \times F P Q_{k t} \leq M C A P_{t}^{p} & \forall t
\end{array}
$$

For Eq. (13), the average defective rate of item $\left(\widetilde{I D R_{l J}}\right)$ and manufacturer's acceptable defective rate $\left(\widetilde{M D R}_{l}\right)$ are uncertain and are converted to crisp values as follows: 


$$
\begin{array}{lr}
\sum_{j} I D R_{i j}^{o} \times I P Q_{i j t} \leq M D R_{i}^{o} \times \sum_{j} I P Q_{i j t} & \forall i, t \\
\sum_{j} I D R_{i j}^{m} \times I P Q_{i j t} \leq M D R_{i}^{m} \times \sum_{j} I P Q_{i j t} & \forall i, t \\
\sum_{j} I D R_{i j}^{p} \times I P Q_{i j t} \leq M D R_{i}^{p} \times \sum_{j} I P Q_{i j t} & \forall i, t
\end{array}
$$

For Eq. (14), the average service level $\left(\widetilde{A S L_{J}}\right)$ and manufacturer's acceptable service level $(\widetilde{M S L})$ are uncertain and are converted to crisp values as follows:

$$
\begin{array}{lr}
\sum_{i} \sum_{j} A S L_{j}^{o} \times I P Q_{i j t} \geq M S L^{o} \times \sum_{i} \sum_{j} I P Q_{i j t} & \forall t \\
\sum_{i} \sum_{j} A S L_{j}^{m} \times I P Q_{i j t} \geq M S L^{m} \times \sum_{i} \sum_{j} I P Q_{i j t} & \forall t \\
\sum_{i} \sum_{j} A S L_{j}^{p} \times I P Q_{i j t} \geq M S L^{p} \times \sum_{i} \sum_{j} I P Q_{i j t} & \forall t
\end{array}
$$

\subsection{Multi-Objective Mixed Integer Linear Programming (MOMILP) model}

To solve supply chain master planning, we apply a two-phase approach. The first phase deals with the multiple-objective possibilistic mixed-integer linear programming model. This converts the fuzzy multiple-objective possibilistic mixed-integer linear programming values to crisp values. The second phase converts the fuzzy multiple-objective possibilistic mixed-integer linear programming values to single-objective possibilistic mixed-integer linear programming values by using the fuzzy goal programming method.

\section{Phase 1}

The crisp multi-objective mixed-integer linear programming model (MOMILP) is stated as follows:

Minimize $Z=\left[Z_{1},-Z_{2}, Z_{3},-Z_{4}\right]$

$$
Z_{1}=T C L_{1}, Z_{2}=T C L_{2}, Z_{3}=T C L_{3}, Z_{4}=T V P
$$

subject to:

$v \in F(v)$,

where $v$ denotes a feasible solution that involves all continuous and binary variables, and $F(v)$ denotes the feasible region involving crisp constraints (25)-(51).

To sum up, the procedures for solving the multi-objective mixed-integer linear programming model can be presented as follows:

i. Generate appropriate values of imprecise and constant parameters, based on the triangular distribution.

ii. Formulate the Linear Programming (LP) model for the supply chain master planning problem of each objective by using Eqs. (1)-(19).

iii. Convert the original fuzzy objective into crisp objectives by using Eqs. (25)-(51), minimizing the total costs of logistics.

iv. Formulate the crisp Multi-Objective Mixed Integer Linear Programming (MOMILP) model according to Eq. (52).

v. Determine the boundaries of each objective by calculating the Positive Ideal Solution (PIS) and Negative Ideal Solution (NIS).

A Multiple Objective Linear Programming (MOLP) problem can be converted into a single-goal linear programming problem by setting the criteria of solutions: Positive Ideal Solution (PIS) and Negative Ideal Solution (NIS) of all objective functions. These can be used to be the boundaries of each objective 
function by the linear programing model, to obtain the maximum and minimum solutions of each objective. The objective functions used to calculate the PIS and NIS values are expressed as follows:

$Z_{1}^{P I S}=$ minimize $T C L^{m}$, $Z_{1}^{N I S}=\operatorname{maximize} T C L^{m}$

$Z_{2}^{P I S}=\operatorname{maximize} T C L^{m}-T C L^{p}$, $Z_{1}^{N I S}=\operatorname{minimize} T C L^{m}-T C L^{p}$

$Z_{3}^{P I S}=\operatorname{minimize} T C L^{o}-T C L^{m}$, $Z_{1}^{N I S}=\operatorname{maximize} T C L^{o}-T C L^{m}$

$Z_{4}^{P I S}=$ maximize $Z_{4}^{N I S}=\operatorname{minimize} T V P$

subject to:

$$
v \in F(v)
$$

vi. Specify linear membership functions for each objective function and constraint as follows:

Linear membership functions for each objective function

$$
\begin{aligned}
& \mu_{1}(v)=\left\{\begin{array}{cc}
1 & \text { if } Z_{1}<Z_{1}^{P I S} \\
Z_{1}^{N I S}-Z_{1} & \text { if } Z_{1}^{P I S} \leq Z_{1} \leq Z_{1}^{N I S} \\
Z_{1}^{N I S}-Z_{1}^{P I S} & \text { if } Z_{1}>Z_{1}^{N I S}
\end{array}\right\} \\
& \mu_{2}(v)=\left\{\begin{array}{cc}
1 & \text { if } Z_{2}>Z_{2}^{P I S} \\
\frac{Z_{2}-Z_{2}^{N I S}}{Z_{2}^{P I S}-Z_{2}^{N I S}} & \text { if } Z_{2}^{N I S} \leq Z_{2} \leq Z_{2}^{P I S} \\
0 & \text { if } Z_{2}>Z_{2}^{N I S}
\end{array}\right\} \\
& \mu_{3}(v)=\left\{\begin{array}{cc}
1 & \text { if } Z_{3}<Z_{3}^{P I S} \\
Z_{3}^{N I S}-Z_{3} & \text { if } Z_{3}^{P I S} \leq Z_{3} \leq Z_{3}^{N I S} \\
\hline Z_{3}^{N I S}-Z_{3}^{P I S} & \text { if } Z_{3}>Z_{3}^{N I S}
\end{array}\right\}
\end{aligned}
$$

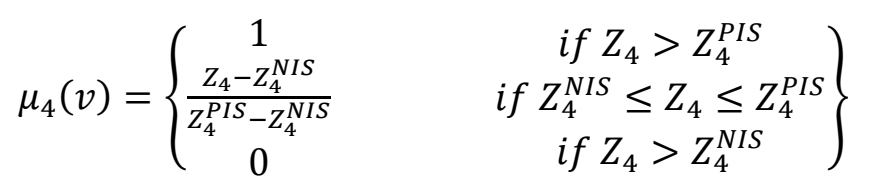

Note: $\mu_{h}(v)$ refers to the satisfaction level of the $h^{\text {th }}$ objective function of the given solution vector $v$. Linear membership functions for demand constraint

$$
\mu_{f}(v)=\left\{\begin{array}{cc}
1 & \text { if } d_{k l t} \leq d_{k l t}^{o} \\
1-\frac{d_{k l t}-d_{k l t}^{o}}{d_{k l t}^{m}-d_{k l t}^{o}} & \text { if } d_{k l t}^{p} \leq d_{k l t} \leq d_{k l t}^{o} \\
0 & \text { if } d_{k l t} \geq d_{k l t}^{p}
\end{array}\right\}
$$

The linear membership functions for minimizing the most likely total costs of logistics, maximizing the lower total costs of logistics, minimizing the higher total costs of logistics, and maximizing the total value of purchasing are described in Appendix.

vii. Convert the crisp multi-objective mixed-integer linear programming model to a single-objective mixed-integer linear programming model by using the Fuzzy Goal Programming (FGP) approach.

\subsection{Fuzzy Goal Programming (FGP) model}

A fuzzy decision is defined in an analogy to non-fuzzy environments "as the selection of activities which simultaneously satisfy objective functions and constraints". A fuzzy decision can be classified into two categories: symmetric and asymmetric fuzzy decision-making. Zimmermann's method can be 
used for symmetric fuzzy decision-making. There is no difference in importance for the weights of objectives and constraints (weightless). In contrast, the Weighted Additive method is an asymmetric fuzzy decision-making method. The objectives and constraints are not equally important and can have different weights.

\section{Phase 2}

\subsubsection{Zimmermann's method}

This approach was first developed by Zimmermann for solving multi-objective linear programming problems. It tries to maximize the lowest or minimum satisfaction degree of objectives, which can guarantee that the satisfaction levels of objectives are higher than the degree of the lowest objective. The mathematical model of Zimmermann's method is expressed as follows:

$\max \lambda=\lambda_{0}$

subject to:

$$
\begin{aligned}
& \lambda_{0} \leq \mu_{h}(v), \quad h=1,2,3,4 \\
& v \in F(v)
\end{aligned}
$$

where $\lambda_{0}$ indicates the minimum satisfaction degree of objective functions, and $F(v)$ denotes the feasible region involving the constraints of the equivalent crisp model.

\subsubsection{Weighted Additive method}

This approach is widely used in vector-objective optimization problems; the basic concept is to use a single utility function to express the overall preference of decision-maker to express the relative importance of criteria (Lai and Hwang, 1994). Its function maximizes the minimum overall satisfaction of fuzzy objective functions and fuzzy constraints. The mathematical model of the Weighted Additive method is expressed as follows:

$\max \lambda=w_{h} \lambda_{h}+\beta_{f} \gamma_{f}$

subject to:

$$
\begin{array}{ll}
\lambda_{h} \leq \mu_{h}(v), & h=1,2,3,4 \\
\gamma_{f} \leq \mu_{f}(v), & f=1 \\
v \in F(v) & \\
\sum_{h=1}^{H} w_{h}+\sum_{f=1}^{F} \beta_{f}=1 & \\
\gamma_{h}, \beta_{f} \geq 0 &
\end{array}
$$

where $\gamma_{f}$ indicates the satisfaction degree of the $f^{\text {th }}$ fuzzy constraint, $w_{h}$ and $\beta_{f}$ are the weighting coefficients of the relative importance among the fuzzy goals and fuzzy constraints, and $F(v)$ denotes the feasible region involving the constraints of the equivalent crisp model.

\section{5. $\alpha$-Cut analysis}

The obtained achievement level may not be enough to satisfy the decision-makers in terms of the objective value. It happens in most cases that a poor performance with one criterion cannot easily be balanced with a good performance on other criteria. The $\alpha$-Cut analysis ensures the decision-makers that the degree of achievement for fuzzy goals and fuzzy constraints is not less than the decisionmakers' minimum allowed satisfaction value $(\alpha)$. 
The following constraints are then added to the model to ensure that the obtained degree of achievement for fuzzy goals and fuzzy constraints is not less than the decision-makers' minimum allowed satisfaction value $(\alpha)$.

$\lambda_{h} \geq \alpha$

$\gamma_{f} \geq \alpha$

$\alpha \in\left[\alpha^{-}, \alpha^{+}\right]$

\section{Case study}

In our case study, the supply chain master planning problem involves four suppliers, a manufacturer, and three distribution centers. Three products are produced by using ten basic purchased items. Table 1 describes the supplier-item matrix where a pair of $(i, j)$ is 1 if supplier $j$ can be supplied item $i$, and 0 , otherwise. In the supplier-item matrix as shown in Table 1, not all suppliers can provide all items. For example, Supplier 1 cannot provide Item 7 and Item 8 . The qualified suppliers or the highest weights of the performance $\left(W_{j}\right)$ of suppliers have been selected through a screening process based on the criteria of price, quality of items, and service level (on-time and correct delivery). The problem is set so that Supplier 1 provides the material with the most expensive price and excellent quality and service level. While Supplier 2 and Supplier 4 sell at a relatively similar medium price, Supplier 2 has a better service level but poorer quality level in relation to Supplier 4. Supplier 3 sells at the cheapest price, but its material is found to have poor quality with a poor service level. Generally, the fuzzy TOPSIS can be used to determine most weights of the performance of the suppliers in multi-criteria decision making for supplier selection, as seen in Table 2. With 4 suppliers, it is found that $W_{j}$ of each supplier is equal to $0.44,0.20,0.14,0.22$, respectively, where Supplier 1 has the highest performance weight and Supplier 3 has the lowest performance weight.

The supply chain master planning is planned for the next 12-month periods. To make parameters close to real practice, the parameters are generated randomly by applying the symmetrical triangular distribution as shown in Table 3. All parameters in Table 3 except the end customer demand are set to be random, based on the uniform distribution. For example, $M S L$, which is the manufacturer's acceptable service level, is set to be random from $83 \%$ to $88 \%$ and is uniformly distributed. The most likely values of each imprecise parameter $(\mathrm{m})$ are random, based on the triangular distribution. The optimistic (o) and pessimistic (p) values vary by $\pm 20 \%$ from this most likely value. Other relevant data are summarized in Table 4 and Table 5. The bill of materials as seen in Table 4 can be used to describe the structure of each final product. For example, two units of Items 1 and 6 , and one unit of Items $2,4,7,9$, and 10 are required to produce Product 1 . In addition, Table 5 shows the storage capacity data. For example, $I V R_{i}$ is equal to $(3,1,2,1,1,3,2,1,2,1)$ units means that the unit storage volume required for Items 1 to 10 is $3,1,2,1,1,3,2,1,2$, and 1 units, respectively.

Table 1

Supplier-item matrix.

\begin{tabular}{lllllllllll}
\hline \multirow{2}{*}{$\begin{array}{l}\text { Supplier } \\
(j)\end{array}$} & 1 & 2 & 3 & 4 & 5 & 6 & 7 & 8 & 9 & 10 \\
\hline 1 & 1 & 1 & 1 & 1 & 1 & 1 & 0 & 0 & 1 & 1 \\
2 & 1 & 1 & 1 & 1 & 1 & 1 & 1 & 1 & 0 & 0 \\
3 & 1 & 1 & 1 & 1 & 0 & 0 & 0 & 0 & 1 & 1 \\
4 & 1 & 1 & 1 & 1 & 0 & 0 & 1 & 1 & 0 & 0 \\
\hline
\end{tabular}


Table 2

Suppliers' performance

\begin{tabular}{lcccc}
\hline Criteria & Supplier 1 & Supplier 2 & Supplier 3 & Supplier 4 \\
\hline Price & Expensive & Medium & Cheap & Medium \\
Quality & Excellent & Low & Low & Good \\
Service level & Excellent & Good & Low & Low \\
\hline
\end{tabular}

Table 3

Set of randomly parameters

\begin{tabular}{|c|c|c|c|c|c|}
\hline Parameters & Random distribution & Units & Parameters & Random distribution & Units \\
\hline MSL & $U(83,88)$ & $\%$ & $S C A P_{j t}^{m}$ & $\frac{\sum_{t} \sum_{i} \sum_{k} \sum_{l}\left(I C R_{i j}^{m} B_{i k} d_{k l t}^{m}\right)}{T} * U(0.5,0.8)$ & units \\
\hline$M D R_{i}$ & $U(5.5,6.5)$ & $\%$ & $U R_{j t}^{m}$ & $U(20,30)$ & $\%$ \\
\hline$A S L_{1}$ & $U(90,95)$ & $\%$ & $T O C_{1 t}$ & $U(150,250)$ & $\$$ \\
\hline$A S L_{2}$ & $U(85,90)$ & $\%$ & $T_{O C C_{2 t}}$ & $U(100,200)$ & $\$$ \\
\hline$A S L_{3}$ & $U(80,85)$ & $\%$ & $\mathrm{TOC}_{3 t}$ & $U(50,150)$ & $\$$ \\
\hline$A S L_{4}$ & $U(80,85)$ & $\%$ & $T_{O C C_{4 t}}$ & $U(100,200)$ & $\$$ \\
\hline$T A C_{1}$ & $U(1,300,1,500)$ & $\$$ & $F V C_{k t}^{m}$ & $U(1,3)$ & $\$$ \\
\hline$T A C_{2}$ & $U(1,100,1,300)$ & $\$$ & $F M H C_{k t}^{m}$ & $\begin{array}{l}\left(\sum_{j} I U P_{i j t}^{m} * B_{i k}\right) \\
+\left(F V C_{k t}^{m} * U(0.005,0.01)\right)\end{array}$ & $\$$ \\
\hline$T A C_{3}$ & $U(900,1,100)$ & $\$$ & $I U P_{i 1 t}^{m}$ & $U(8,12)$ & $\$$ \\
\hline $\mathrm{TAC}_{4}$ & $U(1,100,1,300)$ & $\$$ & $I U P_{i 2 t}^{m}$ & $U(6,10)$ & $\$$ \\
\hline$F C R_{k}^{m}$ & $U(3,5)$ & units & $I U P_{i 3 t}^{m}$ & $U(4,8)$ & $\$$ \\
\hline$M C A P_{t}^{m}$ & $\frac{\sum_{t} \sum_{k} \sum_{l}\left(F C R_{k}^{m} * d_{k l t}^{m}\right)}{T} * U(1.1,1.3)$ & units & $I U P_{i 4 t}^{m}$ & $U(6,10)$ & $\$$ \\
\hline$I E I_{0}$ & $\sum_{k} \sum_{l} B_{i k} d_{k l 1}^{P} * U(0.8,1)$ & units & $I A C_{i j t}^{m}$ & $U(0.1,0.2)^{*} I U P_{i j t}^{m}$ & $\$$ \\
\hline$I D R_{i 1}$ & $U(1,3)$ & $\%$ & $F S C_{k l t}^{m}$ & $U(0.2,0.4)$ & $\$$ \\
\hline$I D R_{i 2}$ & $U(5,7)$ & $\%$ & $F \widetilde{D H C}_{k l t}$ & $F M H C_{k t}^{m} * U(1.05,1.10)$ & $\$$ \\
\hline$I D R_{i 3}$ & $U(5,7)$ & $\%$ & $d_{1 l t}^{m}$ & $N\left(150,10^{2}\right)$ & units \\
\hline$I D R_{i 4}$ & $U(3,5)$ & $\%$ & $d_{2 l t}^{m}$ & $N\left(400,20^{2}\right)$ & units \\
\hline$I C R_{i j}^{m}$ & $U(1,3)$ & units & $d_{3 l t}^{m}$ & $N\left(250,15^{2}\right)$ & units \\
\hline$I H C_{i t}^{m}$ & $\operatorname{Average}_{i}\left(I U P_{i j t}^{m}\right) * U(0.005,0.01)$ & $\$$ & & & \\
\hline
\end{tabular}

Table 4

Bill of materials

\begin{tabular}{lllllllllll}
\hline & \multicolumn{10}{c}{ Item $(i)$} \\
\cline { 2 - 12 } Product $(k)$ & 1 & 2 & 3 & 4 & 5 & 6 & 7 & 8 & 9 & 10 \\
\hline 1 & 2 & 1 & 0 & 1 & 0 & 2 & 1 & 0 & 1 & 1 \\
2 & 1 & 3 & 1 & 0 & 1 & 2 & 0 & 1 & 2 & 2 \\
3 & 1 & 0 & 2 & 1 & 1 & 1 & 3 & 0 & 1 & 1 \\
\hline
\end{tabular}

Table 5

Storage capacity data

\begin{tabular}{lll}
\hline$I V R_{i}$ & $(3,1,2,1,1,3,2,1,2,1)$ & units \\
$F V R_{k}$ & $(5,8,6)$ & units \\
$R W$ & $(18,500)$ & units \\
$S W$ & $(1,800)$ & units \\
$D W_{l}$ & $(13,000,9,000,12,000)$ & units \\
$s_{k}$ & 5 & $\%$ \\
\hline
\end{tabular}

\section{Results}

\subsection{Multiple-Objective Mixed-Integer Linear Programming (MOMILP)}

The multi-objective mixed-integer linear programming model can be used to find the Positive Ideal Solution (PIS) and Negative Ideal Solution (NIS) that are set as the boundaries of each objective. The results can be obtained as follows: 


\section{Table 6}

Positive Ideal Solution (PIS) and Negative Ideal Solution (NIS) of all objective functions

\begin{tabular}{lll}
\hline & Positive Ideal Solution (PIS) & Negative Ideal Solution (NIS) \\
\hline $\begin{array}{l}\text { Minimize the most likely total costs of } \\
\text { logistics }\left(Z_{1}=Z^{m}\right)\end{array}$ & $\$ 1,205,612$ & $\$ 4,268,356$ \\
$\begin{array}{l}\text { Maximize the lower total costs of logistics } \\
\left(Z_{2}=Z^{m}-Z^{o}\right)\end{array}$ & $\$ 371,506$ & $\$ 63,115$ \\
$\begin{array}{l}\text { Minimize the higher total costs of logistics } \\
\left(Z_{3}=Z^{p}-Z^{m}\right)\end{array}$ & $\$ 31,579$ & $\$ 311,766$ \\
\hline Maximize the total value of purchasing $\left(Z_{4}\right)$ & 465,405 units & 183,367 units \\
\hline
\end{tabular}

In Table 6, the objective function minimizes the most likely total costs of logistics. The Positive Ideal Solution (PIS) and Negative Ideal Solution (NIS) of minimizing the most likely total costs of logistics can be calculated by minimizing the most likely total costs of logistics. This yields the Positive Ideal Solution (PIS), which is $\$ 1,205,612$. Maximizing the most likely total costs of logistics yields the Negative Ideal Solution (NIS), which is $\$ 4,268,356$. In contrast, the Positive Ideal Solution (PIS) and Negative Ideal Solution (NIS) of maximizing the total value of purchasing can be calculated by maximizing the total value of purchasing. This yields the Positive Ideal Solution (PIS), which is 465,405 units. Minimizing the total value of purchasing yields the Negative Ideal Solution (NIS), which is 183,367 units.

\subsection{Fuzzy Goal Programming (FGP)}

\subsubsection{Zimmermann's method}

For Zimmermann's method, the importance of each objective function is equal or weightless (fully symmetric). The method maximizes the minimum satisfaction of the objective functions. The results of Zimmermann's method are as follows:

\section{Table 7}

Optimal solutions from Zimmermann's method

$\begin{array}{lc}\text { Overall Satisfaction }(\lambda) & 50.7 \% \\ \text { Minimum possible value of the lower total costs of logistics } & \$ 2,496,000 \\ \left(Z_{2}=Z^{m}-Z^{o}=\$ 219,300\right) & \$ 2,716,000 \\ \text { Minimum possible value of the most likely total costs of logistics } & \\ \left(Z_{1}=Z^{m}=\$ 2,716,000\right) & \$ 2,885,000 \\ \text { Minimum possible value of the higher total costs of logistics } & 326,300 \text { units } \\ \left(Z_{3}=Z^{p}-Z^{m}=\$ 169,800\right) & 50.7 \% \\ \text { Maximum total value of purchasing }\left(Z_{4}\right) & 50.7 \% \\ \text { Satisfaction from minimizing the most likely total costs of logistics }\left(\lambda_{1}\right) & 50.7 \% \\ \text { Satisfaction from maximizing the lower total costs of logistics }\left(\lambda_{2}\right) & 50.7 \% \\ \text { Satisfaction from minimizing the higher total costs of logistics }\left(\lambda_{3}\right) & \\ \text { Satisfaction from maximizing the total value of purchasing }\left(\lambda_{4}\right) & \end{array}$

Based on Table 7, the overall satisfaction $(\lambda)$, which is the maximum value of the minimum satisfaction of the objective functions, is equal to $50.7 \%$. In this case, the satisfaction of each objective is equally set at $50.7 \%$ to conform to the relative importance of each objective function (equal weight or weightless). At $50.7 \%$ satisfaction, the minimum value of the most likely total costs of logistics $\left(Z_{1}\right)$ is $\$ 2,716,000$, the maximum value of the lower total costs of logistics $\left(Z_{2}\right)$ is $\$ 219,300$, the minimum value of the higher total costs of logistics $\left(Z_{3}\right)$ is $\$ 169,800$, and the maximum value of the total value of purchasing $\left(Z_{4}\right)$ is 326,300 units. 


\subsubsection{Weighted Additive method}

The Weighted Additive method allows decision-makers to assign different weights to each objective function based on the importance (asymmetric). The method maximizes each membership function of fuzzy goals and fuzzy constraints multiplied by their corresponding weights and then adds the results together to obtain a linear weighted utility function. For demonstration purposes in this study, the weights of the fuzzy goals are assigned as $w_{1}=0.25, w_{2}=0.25, w_{3}=0.25$, and $w_{4}=0.15$, and the weight of the fuzzy constraint is $\beta_{1}=0.1$. This is because decision-makers decide to give their preferences based on $90 \%$ for the main objective and 10\% for the fuzzy constraint. Then, each of the main objectives is set to be equally important. The optimal solutions of the Weighted Additive method are as follows:

\section{Table 8}

Optimal solutions from Weighted Additive method

\begin{tabular}{lc}
\hline Overall Satisfaction $(\lambda)$ & $62 \%$ \\
Minimum possible value of the lower total costs of logistics & $\$ 2,090,000$ \\
$\left(Z_{2}=Z^{m}-Z^{o}=\$ 103,400\right)$ & $\$ 2,194,000$ \\
Minimum possible value of the most likely total costs of logistics & $\$ 2,246,000$ \\
$\left(Z_{1}=Z^{m}=\$ 2,194,000\right)$ & 345,300 units \\
Minimum possible value of the higher total costs of logistics & $67.7 \%$ \\
$\left(Z_{3}=Z^{p}-Z^{m}=\$ 52,098\right)$ & $13.1 \%$ \\
Maximum total value of purchasing $\left(Z_{4}\right)$ & $92.7 \%$ \\
Satisfaction from minimizing the most likely total costs of logistics $\left(\lambda_{1}\right)$ & $57.4 \%$ \\
Satisfaction from maximizing the lower total costs of logistics $\left(\lambda_{2}\right)$ & $100 \%$ \\
Satisfaction from minimizing the higher total costs of logistics $\left(\lambda_{3}\right)$ & \\
Satisfaction from maximizing the total value of purchasing $\left(\lambda_{4}\right)$ & \\
Satisfaction of demand constraint $\left(\gamma_{1}\right)$ & \\
\hline
\end{tabular}

Based on the results obtained from the Weighted Additive method (Table 8), it was found that the overall satisfaction $(\lambda)$ is higher at $62 \%$, as compared to the overall satisfaction from the Zimmermann's method at $50.7 \%$. In addition, the obtained values of the satisfaction follow the decision-makers' preferences. The achievement level of minimizing the most likely total costs of logistics $\left(\lambda_{1}\right)$ is higher than the achievement level of maximizing the total value of purchasing $\left(\lambda_{4}\right)$. This is because the decision-makers also prioritize the weight of fuzzy goals of the most likely total costs of logistics $\left(\gamma_{1}\right)$ to be higher than the weight of fuzzy goals of the total value of purchasing $\left(\gamma_{4}\right)$. Even though, $\gamma_{2}$ and $\gamma_{3}$ are equally assigned by the decision-makers in this case, their satisfaction values are not equal. There is a trade-off between these two objectives. While one increases, the other needs to decrease. This is explained in the next section of the $\alpha-C u t$ analysis. Referring to aforementioned percentages of the satisfaction of each objective function and constraint, the minimum value of the most likely total costs of logistics $\left(Z_{1}\right)$ is $\$ 2,194,000$, the maximum value of the lower total costs of logistics $\left(Z_{2}\right)$ is $\$ 103,400$, the minimum value of the higher total costs of logistics $\left(Z_{3}\right)$ is $\$ 52,098$, and the maximum value of the total value of purchasing $\left(Z_{4}\right)$ is 345,300 units.

\subsubsection{Alpha-Cut $(\alpha-$ Cut $)$ analysis}

$\alpha$-Cut analysis is a method that can help decision-makers to increase the achievement level of fuzzy objective functions and fuzzy constraints to not be less than their specified minimum allowed satisfaction value $(\alpha)$. In this case, $\alpha^{+}$is 0.507 , which is derived from the optimal satisfaction of Zimmermann's method in which all objective functions are equally important (fully symmetric). $\alpha^{-}$is 0.131 , which is derived from the lowest satisfaction among fuzzy objective functions and constraints of the Weighted Additive method in which the fuzzy objective functions and constraints have unequal importance (asymmetric). Thus, $\alpha$ can be varied from 0.131 to a maximum level of 0.507 by a step size of 0.037 so that the solution can be changed from asymmetric to fully symmetric decision making. 
Based on the Weighted Additive method, the satisfaction from maximizing the lower total costs of logistics $\left(\lambda_{2}\right)$ is equal to 0.131 or $13.1 \%$. This is still lower than the decision-makers' preference, which is set to be at least $25 \%$. In this case, the process of $\alpha$-Cut analysis increases the satisfaction level from maximizing the lower total costs of logistics $\left(\lambda_{2}\right)$ to be more than or equal to $25 \%$. The solutions of $\alpha$ Cut analysis are as follows:

Table 9

Solutions of $\alpha$-Cut analysis

\begin{tabular}{|c|c|c|c|c|c|c|}
\hline & S1 & S2 & S3 & \multicolumn{2}{|c|}{$\mathrm{S} 4$} & S5 \\
\hline$\alpha$-Cut & 0.131 & 0.169 & 0.206 & \multicolumn{2}{|c|}{0.244} & 0.281 \\
\hline Overall satisfaction & 0.615 & 0.610 & 0.607 & \multicolumn{2}{|c|}{0.593} & 0.589 \\
\hline$Z_{1}(\$)$ & $2,205,000$ & $2,325,000$ & $2,378,000$ & \multicolumn{2}{|c|}{$2,470,000$} & $2,481,000$ \\
\hline$Z_{2}(\$)$ & 103,500 & 115,200 & 126,600 & \multicolumn{2}{|c|}{138,300} & 149,700 \\
\hline$Z_{3}(\$)$ & 50,563 & 64,936 & 76,159 & \multicolumn{2}{|c|}{99,026} & 100,200 \\
\hline$Z_{4}$ (units) & 342,300 & 343,800 & 346,600 & \multicolumn{2}{|c|}{353,300} & 376,100 \\
\hline$\lambda_{1}$ & 0.6934 & 0.6742 & 0.6569 & \multicolumn{2}{|c|}{0.6360} & 0.5733 \\
\hline$\lambda_{2}$ & 0.1310 & 0.1690 & 0.2060 & \multicolumn{2}{|c|}{0.2441} & 0.2810 \\
\hline$\lambda_{3}$ & 0.9322 & 0.8809 & 0.8408 & \multicolumn{2}{|c|}{0.7592} & 0.7549 \\
\hline$\lambda_{4}$ & 0.5036 & 0.5250 & 0.5389 & \multicolumn{2}{|c|}{0.5525} & 0.5771 \\
\hline$\gamma_{1}$ & 1 & 1 & 1 & \multicolumn{2}{|c|}{1} & 1 \\
\hline & S6 & S7 & S8 & S9 & $\mathrm{S} 10$ & $\mathrm{~S} 11$ \\
\hline$\alpha-\mathrm{Cut}$ & 0.319 & 0.357 & 0.394 & 0.432 & 0.469 & 0.507 \\
\hline Overall satisfaction & 0.586 & 0.588 & 0.584 & 0.589 & 0.595 & \multirow{10}{*}{ 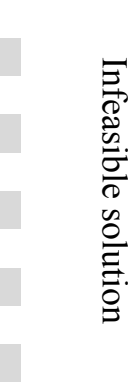 } \\
\hline$Z_{1}(\$)$ & $2,587,000$ & $2,618,000$ & $2,665,000$ & $2,727,000$ & $2,777,000$ & \\
\hline$Z_{2}(\$)$ & 173,400 & 174,200 & 184,600 & 196,300 & 207,700 & \\
\hline$Z_{3}(\$)$ & 120,800 & 122,070 & 136,300 & 143,000 & 154,900 & \\
\hline$Z_{4}$ (units) & 381,400 & 384,000 & 386,500 & 391,200 & 401,800 & \\
\hline$\lambda_{1}$ & 0.5487 & 0.5363 & 0.5232 & 0.5179 & 0.5042 & \\
\hline$\lambda_{2}$ & 0.3576 & 0.3670 & 0.3940 & 0.4320 & 0.4690 & \\
\hline$\lambda_{3}$ & 0.6815 & 0.6806 & 0.6459 & 0.6223 & 0.5996 & \\
\hline$\lambda_{4}$ & 0.5957 & 0.6148 & 0.6209 & 0.6433 & 0.6639 & \\
\hline$\gamma_{1}$ & 1 & 1 & 1 & 1 & 1 & \\
\hline
\end{tabular}

\section{SATISFACTIONS OF EACH OBJECTIVE FUNCTION}

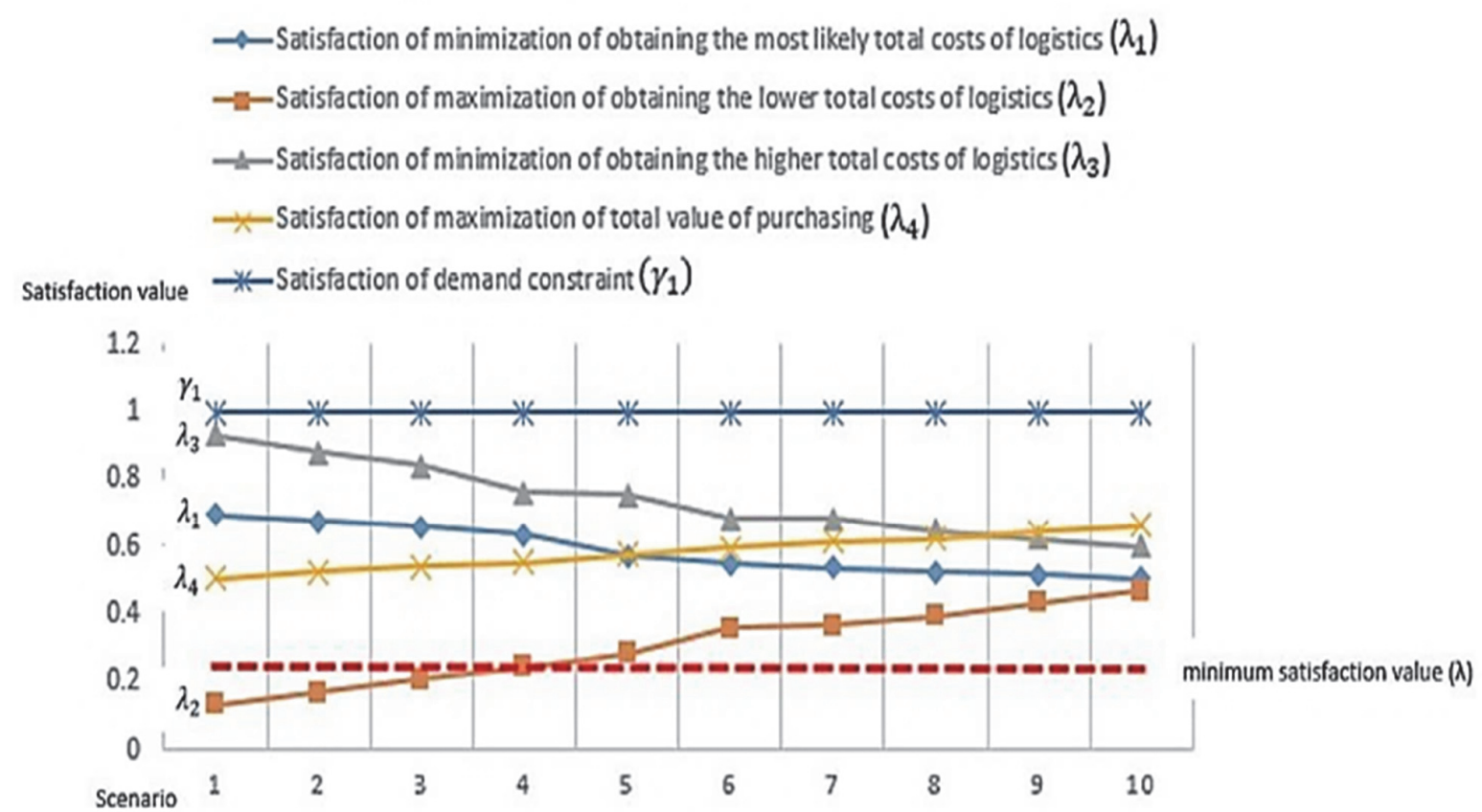

Fig. 3. Satisfactions of each objective function and demand constraint. 
Based on Table 9, when the value of $\alpha$ is varied from 0.131 to a maximum level of 0.507 by a step size of 0.037 , the results can be stated as follows:

(1) The satisfaction from minimizing the most likely total costs of logistics $\left(\lambda_{1}\right)$ and the satisfaction from minimizing the higher total costs of logistics $\left(\lambda_{3}\right)$ keep decreasing. The satisfaction from maximizing the lower total costs of logistics $\left(\lambda_{2}\right)$ and the satisfaction from maximizing the total value of purchasing $\left(\lambda_{4}\right)$ keep increasing.

(2) The satisfaction values of the fuzzy demand constraint $\left(\gamma_{1}\right)$ for all scenarios achieve or nearly achieve $100 \%$ or are at their most likely value. A lower or higher amount of demand would reduce the satisfaction values of the total costs of logistics and the total value of purchasing.

(3) The results show that when the total costs of logistics are high, the total value of purchasing is also high and vice versa. This is because one objective minimizes the total costs of logistics by selecting suppliers who can provide the cheapest item while the other conflicting objective maximizes the total value of purchasing by selecting suppliers who can provide cheap item costs with good quality and a better service level.

(4) Scenario 5 (S5) is a break-even point where the satisfaction values of each fuzzy objective and constraint can satisfy the decision-makers (higher than 25\%). It is the last point where the achievement levels of Objective 1 and Objective $4\left(\lambda_{1} \geq \lambda_{4}\right)$ still follow their assigned weights that were imposed by the decision-makers, to obtain a linear weighted utility function $\left(w_{1} \geq w_{4}\right)$.

(5) Scenario 11 (S11) is an infeasible case due to the trade-off between the satisfaction from maximizing the lower total costs of logistics $\left(\lambda_{2}\right)$ and the satisfaction from minimizing the higher total costs of logistics $\left(\lambda_{3}\right)$. The model cannot find a mutual solution that yields an equal satisfaction value of $50.7 \%$, as suggested by Zimmermann's method.

In summary, Figure 3 can be used to present the overall results of our study for the lower total costs of logistics. However, the graph and possible intersection depend on each case, in which there is no generic solution. Decision-makers are required to select the best available scenarios by analyzing and interpreting these achievement levels in relation to their corresponding weights and preferences. For instance, to pass the required minimum satisfaction value $(\lambda)$ in this study, we should choose the results from Scenario5-Scenario10. In Scenario 5, the achievement level from minimizing the most likely total costs of logistics $\left(\lambda_{1}\right)$ is found to be equal to the achievement level from maximizing the total value of purchasing $\left(\lambda_{4}\right)$. This is the point where the system can simultaneously and equally achieve the highest total costs of logistics and total value of purchasing.

In addition, none of the achievement levels at this point had used the weights assigned in the linear weighted utility function, imposed by the decision-makers. However, moving further away from Scenario 5, the results show that the achievement level from maximizing the total value of purchasing would be increased beyond all achievement levels related to the total costs of logistics. This can conflict with the decision-makers' preferences where they seem to put more emphasis on minimizing the total costs of logistics than on maximizing the total value of purchasing.

\section{Table 10}

Results of Scenario 5

\begin{tabular}{ll}
\hline Minimum possible value of the lower total costs of logistics & $\$ 2,331,300$ \\
$\left(Z_{2}=Z^{m}-Z^{o}=\$ 149,700\right)$ & $\$ 2,481,000$ \\
$\begin{array}{l}\text { Minimum possible value of the most likely total costs of logistics } \\
\left(Z_{1}=Z^{m}=\$ 2,481,000\right)\end{array}$ & $\$ 2,581,200$ \\
$\begin{array}{l}\text { Minimum possible value of the higher total costs of logistics } \\
\left(Z_{3}=Z^{p}-Z^{m}=\$ 100,200\right)\end{array}$ & 376,100 units \\
\hline
\end{tabular}




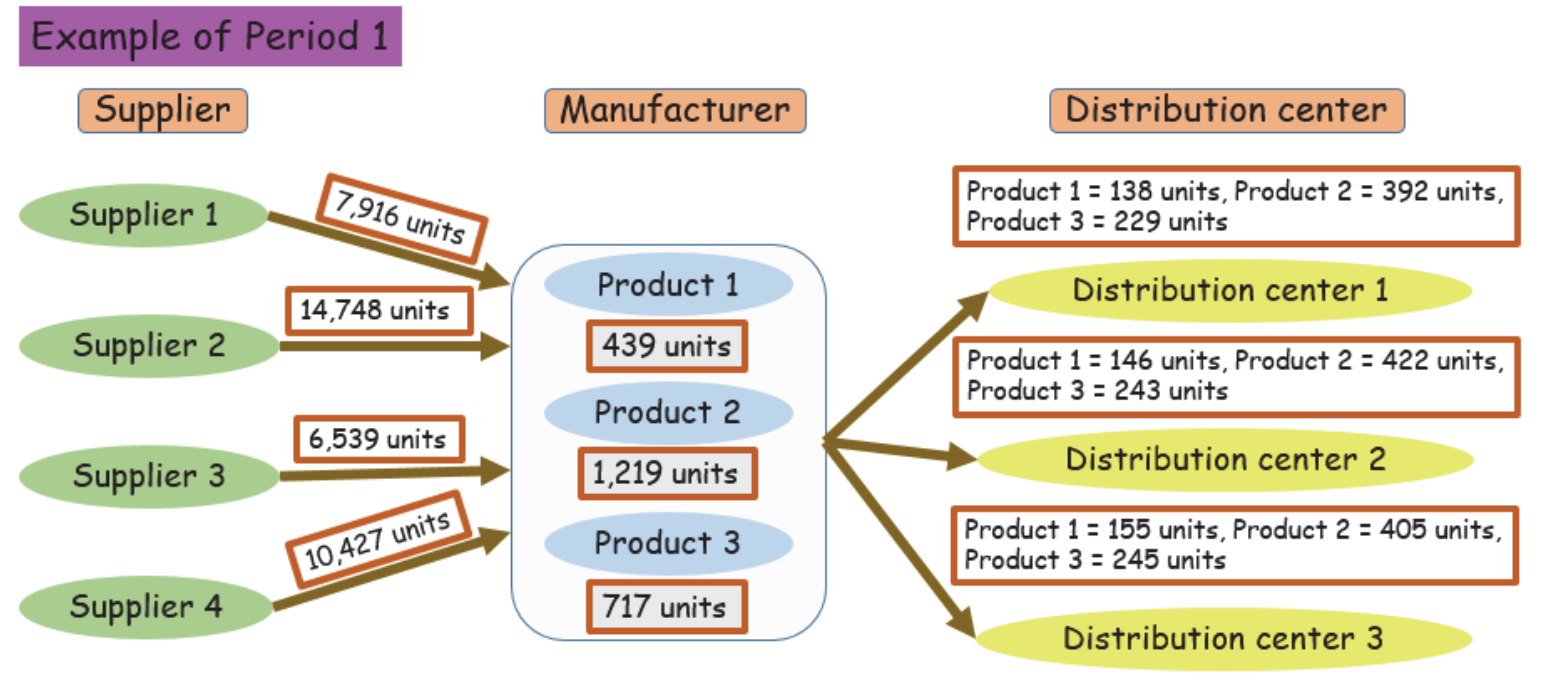

Fig. 4. Structure of supply chain master planning (Period 1)

Based on the result of Scenario 5 as shown in Table 10, the minimum possible value of the lower total costs of logistics is $\$ 2,331,300$, the minimum possible value of the most likely total costs of logistics is $\$ 2,481,000$, the minimum possible value of the higher total costs of logistics is $\$ 2,581,200$, and the maximum value of the total value of purchasing is 376,100 units. In each period, various material items have to be ordered from four suppliers, produced by the manufacturer, and shipped to each distribution center. These units are the model's decision variables. For instance, in period 1, 7,916 units (Item 6, 9, and 10) are bought from Supplier 1, and produced to be Product 1, Product 2, and Product 3. Then, 138, 146, and 155 units of Product 1 are shipped to Distribution center 1, Distribution center 2, and Distribution center 3, respectively. Units bought from other suppliers and the shipment of other products can be seen in Figure 4.

\section{Conclusions}

Supply chain master planning integrates procurement planning, production planning, and distribution planning to satisfy customer requirements and achieve a competitive advantage. It is a complex decision-making process that a decision-maker must face, resulting from data uncertainty, lacking or misleading information, and conflicting objectives, emerging from aligning the goals from different supply chain echelons. This paper proposed an integrated approach with the fuzzy multi-objective linear programming model and $\alpha$-Cut analysis to ensure decision-makers that all objectives are taken into consideration simultaneously, and the degree of achievement for any fuzzy goals and fuzzy constraints is not less than the decision-maker's minimum allowed satisfaction value.

In practice, the importance of each objective is not normally equal. As a result, fuzzy multi-objective linear programming with the Weighted Additive method was introduced into supply chain master planning, to assign different weights to various criteria. This formulation can effectively handle the imprecision of input data and the different importance of criteria in the supply-chain master planning problem. In the model, the $\alpha$-Cut analysis can be utilized to ensure that the obtained results can satisfy decision-makers, based on their minimum allowed satisfaction value.

In this study, the supply chain master planning problem consists of four qualified suppliers, a manufacturer and three distribution centers in which three products are produced based on ten basic purchased items. This study attempts to balance two conflicting objectives: (1) minimizing the total costs of logistics, and (2) maximizing the total value of purchasing, with imprecise operating costs, customer demand, production capacity, manufacturer's acceptable defective rate, and manufacturer's acceptable service level. To balance these two conflicting objectives, the model has to push the three prominent points with the triangular possibility distribution toward the left (as cost minimization) by 
minimizing the most likely total costs of logistics $\left(Z_{1}\right)$, maximizing the lower total costs of logistics $\left(Z_{2}\right)$, and minimizing the higher cost of logistics $\left(Z_{3}\right)$, while maximizing the total value of purchasing $\left(Z_{4}\right)$. Possibilistic Linear Programming (PLP) with the triangular possibility distribution can provide realistic results, which are better than a typical deterministic approach as PLP can handle ambiguous data and suggest a range of possible optimal values. PLP helps decision-makers to be aware of possible outcomes from the optimistic cases (best situation), the most likely case (normal situation), and the pessimistic case (worst situation). Therefore, decision-makers can well-prepare themselves in advance for these situations.

Our results showed that the Weighted Additive method with $\alpha-C u t$ analysis can improve the achievement level of the membership function of fuzzy objectives and constraints. As the model balances the two conflicting objectives, an optimal selection point where the satisfaction values of both objectives approach the break-even point can be identified. This is the point where we can balance the two objectives and satisfy the required minimum satisfaction value from decision-makers for all objectives and constraints.

The main limitation of our proposed approach is the assumption of the triangular possibility distribution that represents imprecise data. Decision-makers should generate and obtain appropriate distributions based on subjective judgment and historical resources. In addition, future researchers can also explore different levels of the relative importance of individual goals, to better suit their practical applications.

\section{References}

Avci, M. G., \& Selim, H. (2018). A multi-objective simulation-based optimization approach for inventory replenishment problem with premium freights in convergent supply chains. Omega, 80 , $153-165$

Arani, H. V., \& Torabi, S. A. (2018). Integrated material-financial supply chain master planning under mixed uncertainty. Information Sciences, 423, 96-114.

Azizi, A., Aikhuele, D. O., \& Souleman, F. S. (2015). A Fuzzy TOPSIS Model to Rank Automotive Suppliers. Procedia Manufacturing, 2, 159-164.

Batarfi, R., Jaber, M. Y., \& Zanoni, S. (2016). Dual-channel supply chain: A strategy to maximize profit. Applied Mathematical Modelling, 40(21-22), 9454-9473.

Bellman, R. E., \& Zadeh, L. A. (1970). Decision-making in a fuzzy environment. Management Science, 17(4), B-141.

Bilir, C., Ekici, S. O., \& Ulengin, F. (2017). An integrated multi-objective supply chain network and competitive facility location model. Computers \& Industrial Engineering, 108, 136-148.

Bittante, A., Pettersson, F., \& Saxén, H. (2018). Optimization of a small-scale LNG supply chain. Energy, 148, 79-89.

Bodjanova, S. (2002). A generalized $\alpha$-cut. Fuzzy Sets and Systems, 126(2), 157-176.

Chan, F. T., Chung, S. H., \& Wadhwa, S. (2005). A hybrid genetic algorithm for production and distribution. Omega, 33(4), 345-355.

Chen, C. T., Lin, C. T., \& Huang, S. F. (2006). A fuzzy approach for supplier evaluation and selection in supply chain management. International Journal of Production Economics, 102(2), 289-301.

Dubois, D., Foulloy, L., Mauris, G., \& Prade, H. (2004). Probability-possibility transformations, triangular fuzzy sets, and probabilistic inequalities. Reliable Computing, 10(4), 273-297.

Fathollahi-Fard, A. M., \& Hajiaghaei-Keshteli, M. (2018). A stochastic multi-objective model for a closed-loop supply chain with environmental considerations. Applied Soft Computing, 69, 232-249.

García-Díaz, J. C., Pulido-Rojano, A., \& Giner-Bosch, V. (2017). Bi-objective optimization of a multihead weighing process. European Journal of Industrial Engineering, 11(3), 403-423.

Ghaithan, A. M., Attia, A., \& Duffuaa, S. O. (2017). Multi-objective optimization model for a downstream oil and gas supply chain. Applied Mathematical Modelling, 52, 689-708.

Hajghasem, M. (2016). Optimal routing in supply chain aimed at minimizing vehicle cost and supply. Procedia Economics and Finance, 36(1), 353-362. 
Hisjam, M., Guritno, A. D., Supriyatno, N., \& Tandjung, S. D. (2015). A Sustainable Partnership Model among Supply Chain Players in Wooden Furniture Industry Using Goal Programming. Agriculture and Agricultural Science Procedia, 3, 154-158.

Nezhad, A., Roghanian, E., \& Azadi, Z. (2013). A fuzzy goal programming approach to solve multiobjective supply chain network design problems. International Journal of Industrial Engineering Computations, 4(3), 315-324.

Kabak, Ö., \& Ülengin, F. (2011). Possibilistic linear-programming approach for supply chain networking decisions. European Journal of Operational Research, 209(3), 253-264.

Kim, J., Do Chung, B., Kang, Y., \& Jeong, B. (2018). Robust optimization model for closed-loop supply chain planning under reverse logistics flow and demand uncertainty. Journal of Cleaner Production, 196, 1314-1328.

Koleva, M. N., Calderón, A. J., Zhang, D., Styan, C. A., \& Papageorgiou, L. G. (2018). Integration of environmental aspects in modelling and optimisation of water supply chains. Science of The Total Environment, 636, 314-338.

Kumar, M., Vrat, P., \& Shankar, R. (2004). A fuzzy goal programming approach for vendor selection problem in a supply chain. Computers \& Industrial Engineering, 46(1), 69-85.

Kumar, S., Kumar, S., \& Barman, A. G. (2018). Supplier selection using fuzzy TOPSIS multi criteria model for a small scale steel manufacturing unit. Procedia Computer Science, 133, 905-912.

Lai, Y. J., \& Hwang, C. L. (1994). Fuzzy multiple objective decision making. In Fuzzy Multiple Objective Decision Making(pp. 139-262). Springer, Berlin, Heidelberg.

Naeni, L. M., \& Salehipour, A. (2011). Evaluating fuzzy earned value indices and estimates by applying alpha cuts. Expert Systems with Applications, 38(7), 8193-8198.

Nikolopoulou, A., \& Ierapetritou, M. G. (2012). Hybrid simulation based optimization approach for supply chain management. Computers \& Chemical Engineering, 47, 183-193.

Nixon, J. D., Dey, P. K., Davies, P. A., Sagi, S., \& Berry, R. F. (2014). Supply chain optimisation of pyrolysis plant deployment using goal programming. Energy, 68, 262-271.

Pariazar, M., \& Sir, M. Y. (2018). A multi-objective approach for supply chain design considering disruptions impacting supply availability and quality. Computers \& Industrial Engineering, 121, 113-130.

Pires, M. C., \& Frazzon, E. M. (2016). On the research of linear programming solving methods for non-hierarchical spare parts supply chain planning. IF AC-PapersOnLine, 49(30), 198-203.

Pibernik, R., \& Sucky, E. (2007). An approach to inter-domain master planning in supply chains. International Journal of Production Economics, 108(1-2), 200-212.

Pires, M. C., Frazzon, E. M., Danielli, A. M. C., Kück, M., \& Freitag, M. (2018). Towards a simulationbased optimization approach to integrate supply chain planning and control. Procedia CIRP, 72, 520-525.

Roy, D., Krishnamurthy, A., Heragu, S. S., \& Malmborg, C. J. (2014). Blocking effects in warehouse systems with autonomous vehicles. IEEE Transactions on Automation Science and Engineering, 11(2), 439-451.

Rudberg, M., \& Thulin, J. (2009). Centralised supply chain master planning employing advanced planning systems. Production Planning and Control, 20(2), 158-167.

Simić, D., Kovačević, I., Svirčević, V., \& Simić, S. (2017). 50 years of fuzzy set theory and models for supplier assessment and selection: A literature review. Journal of Applied Logic, 24, 85-96.

Spitter, J. M., Hurkens, C. A., De Kok, A. G., Lenstra, J. K., \& Negenman, E. G. (2005). Linear programming models with planned lead times for supply chain operations planning. European Journal of Operational Research, 163(3), 706-720.

Subulan, K., Taşan, A. S., \& Baykasoğlu, A. (2015). A fuzzy goal programming model to strategic planning problem of a lead/acid battery closed-loop supply chain. Journal of Manufacturing Systems, 37, 243-264.

Tsai, C. C., Chu, C. H., \& Barta, T. A. (1997). Modeling and analysis of a manufacturing cell formation problem with fuzzy mixed-integer programming. IIE transactions, 29(7), 533-547. 
Önüt, S., Gülsün, B., Tuzkaya, U. R., \& Tuzkaya, G. (2008). A two-phase possibilistic linear programming methodology for multi-objective supplier evaluation and order allocation problems. Information Sciences, 178(2), 485-500.

Vaziri, S., Zaretalab, A., Esmaeili, M., \& Niaki, S. T. A. (2018). An integrated production and procurement design for a multi-period multi-product manufacturing system with machine assignment and warehouse constraint. Applied Soft Computing, 70, 238-262.

Werro, N. (2015). Fuzzy Classification of Online Customers(Vol. 44). Heidelberg: Springer.

Yang, Y., Li, X. R., \& Han, D. (2016). An improved $\alpha$-cut approach to transforming fuzzy membership function into basic belief assignment. Chinese Journal of Aeronautics, 29(4), 1042-1051.

Zhang, X., Ma, W., \& Chen, L. (2014). New similarity of triangular fuzzy number and its application. The Scientific World Journal, 2014.

Zimmermann, H. J. (1978). Fuzzy programming and linear programming with several objective functions. Fuzzy Sets and Systems, 1(1), 45-55.

\section{Appendix}

1. Linear membership function

Linear membership functions for minimization goals and maximization goals are given as follows:

Linear membership functions for the minimization goals (minimize the most likely total costs of logistics $\left(Z_{1}\right)$ and minimize the higher cost of logistics $\left(Z_{3}\right)$ )

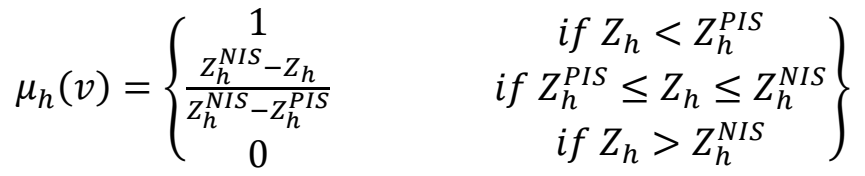

Linear membership functions for the maximization goals (maximize the lower total costs of logistics $\left(Z_{2}\right)$ and maximize total value of purchasing $\left(Z_{4}\right)$ )

$\mu_{h}(v)=\left\{\begin{array}{cc}1 & \text { if } Z_{h}>Z_{h}^{P I S} \\ Z_{h}-Z_{h}^{N I S} & \text { if } Z_{h}^{N I S} \leq Z_{h} \leq Z_{h}^{P I S} \\ \hline Z_{h}^{P I S}-Z_{h}^{N I S} & \text { if } Z_{h}>Z_{h}^{N I S} \\ 0 & \text { is }\end{array}\right\}$

Linear membership function for a fuzzy constraint (fuzzy demand constraint) is given as follows:

Linear membership functions for a fuzzy constraint

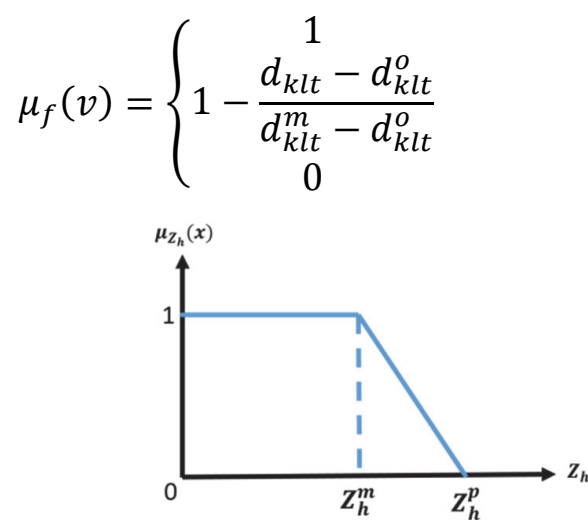

(a)

$$
\left.\begin{array}{c}
\text { if } d_{k l t} \leq d_{k l t}^{o} \\
d_{k l t}^{p} \leq d_{k l t} \leq d_{k l t}^{o} \\
\text { if } d_{k l t} \geq d_{k l t}^{p}
\end{array}\right\}
$$

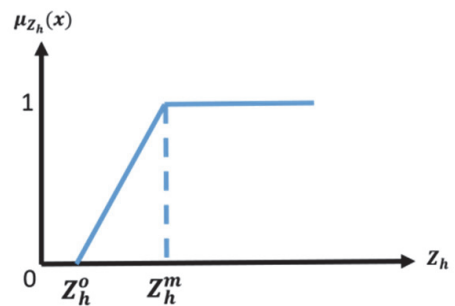

(b)

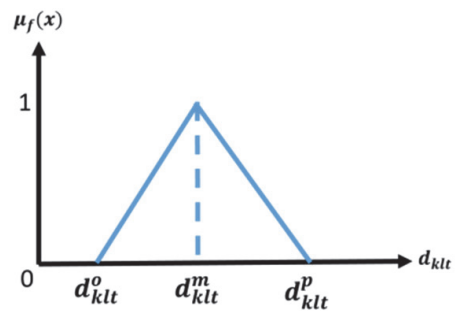

(c)

Fig. 5. Linear membership functions: (a) minimization goals, (b) maximization goals, (c) fuzzy constraint 


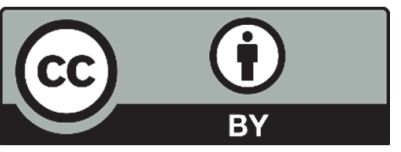

(C) 2019 by the authors; licensee Growing Science, Canada. This is an open access article distributed under the terms and conditions of the Creative Commons Attribution (CC-BY) license (http://creativecommons.org/licenses/by/4.0/). 